\title{
The financial accelerator in an estimated New Keynesian model ${ }^{\text {is }}$
}

\author{
Ian Christensen ${ }^{\mathrm{a}}$, Ali Dib ${ }^{\mathrm{b}, *}$ \\ a Monetary and Financial Analysis Department, Bank of Canada, Canada \\ b International Department, Bank of Canada. 234 Wellington Street, Ottawa, ON K1A 0G9, Canada
}

Received 5 April 2006; revised 23 April 2007

Available online 9 June 2007

\begin{abstract}
This paper estimates and simulates a sticky-price dynamic stochastic general-equilibrium model with a financial accelerator, à la Bernanke et al. [Bernanke, B., Gertler, M., Gilchrist, S., 1999. The financial accelerator in a quantitative business cycle framework. In: Handbook of Macroeconomics. North-Holland, Amsterdam], to assess the importance of the financial accelerator mechanism in fitting the data and its role in the amplification and propagation of transitory shocks. Structural parameters of two models, one with and one without a financial accelerator, are estimated using a maximum-likelihood procedure and post-1979 US data. The estimation and simulation results provide quantitative evidence in favor of the financial-accelerator model. The model without a financial accelerator is statistically rejected in favor of a model with it. The presence of the financial accelerator amplifies and propagates the effects of demand shocks on investment, but it dampens those of supply shocks. However, we find that the importance of the financial accelerator for output fluctuations is relatively minor.

Crown Copyright $\odot 2007$ Published by Elsevier Inc. All rights reserved.
\end{abstract}

JEL classification: E30; E32; E37; E44; E50

Keywords: Business cycles; Financial accelerator; Investment shocks; Sticky prices

\section{Introduction}

Policy-makers, academics, and the business media often follow and discuss credit market conditions extensively. The regular public communications of central banks analyze interest rate spreads or discuss recent trends in the growth of business lending. This discussion reflects a view that the ability of firms to obtain financing plays an active role in investment behavior. Bernanke and Gertler (1989) show that the presence of asymmetric information in credit markets can give the balance sheet conditions of borrowers a role to play in the business cycle through their impact on the cost of external finance. The procyclical nature of net worth leads the wedge between the cost of external finance and internal funds, the external finance premium, to fall during booms and to rise during recessions. Bernanke et al. (1999) and others, including Kiyotaki and Moore (1997) and Carlstrom and Fuerst (1997), demonstrate that these financial frictions may significantly amplify the magnitude and the persistence of fluctuations in economic activity.

\footnotetext{
The views expressed in this paper are of the authors and no responsibility for them should be attributed to the Bank of Canada.

* Corresponding author. Fax: 16137827658.

E-mail address: ADib@bankofcanada.ca (A. Dib).
} 
Despite this interest among researchers, mainstream macroeconomic models used for monetary policy analysis, such as the models used by Christiano et al. (2005), contain no role for financial frictions.

One reason for the omission of financial frictions from standard models is that there is little agreement about their importance for business cycle fluctuations. As a result, quantifying the importance of credit market frictions continues to be the subject of much research. To this end, we estimate a sticky-price dynamic stochastic general-equilibrium (DSGE) model similar to that of Ireland (2003), but with the addition of financial frictions as described in Bernanke et al. (1999). We investigate whether these financial frictions can improve the estimated model's ability to account for key features of the data, particularly those related to output and investment. We also assess the nature of the role it plays in the estimated model's dynamics.

Based on earlier work by Bernanke and Gertler (1989), Bernanke et al. (1999) develop a model in which there is a two-way link between the borrowing costs of firms and their net worth. ${ }^{1}$ This link has come to be known as the "financial accelerator." In this model, entrepreneurs, who borrow funds to undertake investment projects, face an external finance premium that rises when their leverage increases. A tightening in monetary policy, for example, reduces the return on capital resulting in a decline in the net worth of firms. Declines in net worth increase firm leverage, leading to further raising in external financing costs and reducing the demand for capital. The drop in demand for capital reinforces the decline in its value. This mechanism is often called an "accelerator" effect, because the lower price of capital has a feedback effect, further lowering the net worth of firms.

Carlstrom and Fuerst (1997) first demonstrated the quantitative importance of the Bernanke and Gertler (1989) mechanism, finding that it could produce a hump-shaped output response to shocks in an otherwise standard real business cycle model. The propagation brought about by the financial friction allows the model to better match this key feature of the data, but it did not amplify the response of output. Using a sticky-price model calibrated to postwar US data, Bernanke et al. (1999) show that a different setup for the financial-accelerator mechanism both amplifies the impact of shocks and provides a quantitatively important mechanism that propagates shocks at business cycle frequencies. $^{2}$

In this paper, we develop and estimate a sticky-price DSGE model that includes the financial-accelerator mechanism proposed by Bernanke et al. (1999). ${ }^{3}$ Our model, however, differs from Bernanke et al.'s in two important ways. First, the debt contracts in the model are written in terms of the nominal interest rate, which better reflects the nature of debt contracts in the United States. This adds the additional possibility of debt-deflation effects as in Fisher (1933). Second, following Ireland (2003), we allow monetary policy to be characterized by a modified Taylor-type rule, under which the monetary authority adjusts short-term nominal interest rates in response to inflation, output, and money-growth changes. ${ }^{4}$ This is potentially important because the conduct of the monetary authorities will be an important element determining the quantitative importance of the financial accelerator. For example, Bernanke et al. (1999) have noted that policy rules that stabilize output will also counteract, and may eliminate, the impact of the financial accelerator on output or investment (see Fukunaga, 2002 for an example). ${ }^{5}$

We use our model to empirically evaluate the importance of the financial accelerator in the amplification and propagation of the effects of transitory shocks to the economy. We estimate the main structural parameters of two versions of the model: a model that includes a financial accelerator and a model without it. We then assess the ability of each model to account for key features of the data. To estimate the models, we use a maximum-likelihood procedure with a Kalman filter and post-1979 US macro data on output, investment, real balances, the nominal interest rate, and inflation. We use data on investment because financial frictions exert an influence directly on investment behavior.

\footnotetext{
1 An alternative approach is to introduce financial frictions by giving financial intermediaries an ability to change credit conditions without a change in borrower creditworthiness. See Cook (1999) for an example.

2 Subsequent work using the Bernanke et al. (1999) model for other countries has provided similar results (see Hall, 2001 for the United Kingdom and Fukunaga, 2002 for Japan). A number of studies have used this financial-accelerator mechanism to account for macroeconomic developments at times of financial crisis. Cespedes et al. (2004), Gertler et al. (2003), Tovar (2006), and Elekdag et al. (2006) consider the case of open economies in emerging markets. Christiano et al. (2003) use the financial accelerator in their analysis of the Great Depression in the United States.

3 As in previous research on the financial accelerator, we use a closed economy model for the US because it is a large economy where external linkages are relatively small.

4 As in Ireland (2003) the household's utility function in our model is non-separable in consumption and real balances. Since this allows money demand shocks to affect aggregate fluctuations, the monetary authority can respond to money-growth directly.

5 See Bernanke et al. (1999). The effects of the financial accelerator may, nonetheless, show up elsewhere, such as in the size of the monetary policy response required to dampen output fluctuations.
} 
In addition, investment data are required to identify and precisely estimate the capital adjustment cost and capital share parameters. Estimating these two versions of the model allows us to econometrically test for the presence of a financial-accelerator mechanism using the likelihood-ratio test.

Our main findings are as follows. The likelihood-ratio test easily rejects the estimated model with no financial accelerator in favor of the one that includes it. Thus, the financial accelerator improves the model's fit with the data. The estimate of a key parameter in the financial accelerator mechanism, the elasticity of the external finance premium with respect to the firm leverage, is statistically significant and close to values used in typical calibrations. Finally, the model with a financial accelerator generates business cycles moments the closest to those observed in the data.

We also consider the nature of the role played by the financial accelerator in the estimated model. The impulseresponse functions show that introducing the financial accelerator greatly amplifies and propagates the effects of the demand shocks on investment, while it dampens those of the supply shocks. These results are similar to the findings in Iacoviello (2005) who attributes these differential effects to the nominal debt contracts in his model. The effect of the accelerator on output fluctuations is relatively minor. One reason for this is that the monetary authority responds more aggressively to output variations in the model with the financial accelerator in order to stabilize the economy. We also find that an investment-specific shock is important for the empirical success of our model. Fisher (2002) and Justiniano and Primiceri (2006) argue that these types of shocks play an important role in business cycle fluctuations.

These findings contrast with those reported by Meier and Müller (2006), who consider the role of the Bernanke et al. (1999)-style financial accelerator in the monetary transmission mechanism. They estimate their model with US data by matching impulse responses with the empirical impulse responses to a monetary policy shock from a vector autoregression. Their findings attribute an important role to capital adjustment costs, but only a marginal role to the accelerator in explaining the transmission of monetary policy shocks. As a result, Meier and Müller (2006) argue that little is lost if DSGE models do not incorporate financial-accelerator effects. We find that the accelerator mechanism plays an important role in the transmission of monetary policy shocks. In addition, as Meier and Müller (2006) acknowledge, their assessment is based solely on the accelerator's role in the transmission of monetary shocks. We find that the accelerator plays a role in explaining the response of macro variables to a variety of other shocks, particularly an investment-specific technology shock.

This paper is organized as follows. Section 2 describes the model. Section 3 describes the data and the econometric method used to estimate the models. Section 4 discusses the empirical results and Section 5 concludes.

\section{The model}

Our basic model is a closed-economy DSGE model similar to that of Ireland (2003). The key addition to this model is a financial-accelerator mechanism proposed by Bernanke et al. (1999). As a result, we assume that the economy is characterized by three types of rigidities: price stickiness, capital adjustment costs, and financial market frictions.

The economy is populated by a representative household, a monetary authority, and three types of producers: entrepreneurs, capital producers, and retailers. Entrepreneurs produce intermediate goods. They borrow from a financial intermediary that converts household deposits into business financing for the purchase of capital. The presence of asymmetric information between entrepreneurs and lenders creates a financial friction that makes the entrepreneurial demand for capital depends on their financial position. Capital producers build new capital and sell it to the entrepreneurs. Retailers set nominal prices in a staggered fashion à la Calvo (1983) and Yun (1996). ${ }^{6}$ This nominal rigidity gives monetary policy an influence on real activity in the short run.

\subsection{Households}

The representative household derives utility from consumption, $c_{t}$; real money balances, $M_{t} / p_{t}$; and leisure, $1-h_{t}$. Its preferences are described by the following expected utility function:

$$
U_{0}=E_{0} \sum_{t=0}^{\infty} \beta^{t} u\left(c_{t}, M_{t} / p_{t}, h_{t}\right),
$$

6 Ireland (2003) introduces price stickiness using a quadratic price-adjustment cost function. 
where $\beta \in(0,1)$ is the discount factor, $M_{t}$ is holdings of nominal money balances, $h_{t}$ is labor supply, and $p_{t}$ is the consumer price level. The single-period utility function is specified as:

$$
u(\cdot)=\frac{\gamma e_{t}}{\gamma-1} \log \left[c_{t}^{\frac{\gamma-1}{\gamma}}+b_{t}^{1 / \gamma}\left(\frac{M_{t}}{p_{t}}\right)^{\frac{\gamma-1}{\gamma}}\right]+\eta \log \left(1-h_{t}\right),
$$

where $\gamma$ and $\eta$ are positive structural parameters that denote the constant elasticity of substitution between consumption and real balances, and the weight on leisure in the utility function, respectively. We interpret $e_{t}$ as a taste (preference) shock for consumption, while $b_{t}$ is interpreted as a money-demand shock. These shocks follow first-order autoregressive processes:

$$
\log \left(e_{t}\right)=\rho_{e} \log \left(e_{t-1}\right)+\varepsilon_{e t},
$$

and

$$
\log \left(b_{t}\right)=\left(1-\rho_{b}\right) \log (b)+\rho_{b} \log \left(b_{t-1}\right)+\varepsilon_{b t},
$$

where $\rho_{e}, \rho_{b} \in(-1,1)$ are autoregressive coefficients, $b$ is constant, and the serially uncorrelated shocks $\varepsilon_{e t}$ and $\varepsilon_{b t}$ are normally distributed with zero means and standard deviations $\sigma_{e}$ and $\sigma_{b}$, respectively.

The representative household enters period $t$ with $D_{t-1}$ units of nominal deposits in a financial intermediary, and nominal money balances, $M_{t-1}$. While deposits, $D_{t}$, pay the gross nominal interest rate, $R_{t}$, between $t$ and $t+1$, money balances, $M_{t}$, are money held outside of banks (cash) that bear no interest. ${ }^{7}$ During period $t$, the household supplies labor to the entrepreneur firms, for which it receives factor payment $W_{t} h_{t}$, where $W_{t}$ is the economy-wide nominal wage. Furthermore, the household receives a lump-sum transfer from the monetary authority, $T_{t}$, as well as dividend payments, $\Omega_{t}$, from retailer firms. The household allocates these funds to consumption, $c_{t}$, money holdings, $M_{t}$, and nominal deposits, $D_{t}$. The household's budget constraint, in nominal terms, is

$$
P_{t} c_{t}+M_{t}+D_{t} \leqslant W_{t} h_{t}+R_{t-1} D_{t-1}+M_{t-1}+T_{t}+\Omega_{t} .
$$

The representative household chooses $c_{t}, M_{t}, h_{t}$, and $D_{t}$ in order to maximize its expected lifetime utility (1) subject to (2) and the budget constraint (5). The first-order conditions for this optimization problem are:

$$
\begin{aligned}
& \frac{e_{t} c_{t}^{-\frac{1}{\gamma}}}{c_{t}^{\frac{\gamma-1}{\gamma}}+b_{t}^{1 / \gamma} m_{t}^{\frac{\gamma-1}{\gamma}}}=\lambda_{t} ; \\
& \frac{e_{t} b_{t}^{1 / \gamma} m_{t}^{-\frac{1}{\gamma}}}{c_{t}^{\frac{\gamma-1}{\gamma}}+b_{t}^{1 / \gamma} m_{t}^{\frac{\gamma-1}{\gamma}}}=\lambda_{t}-\beta E_{t}\left(\frac{\lambda_{t+1}}{\pi_{t+1}}\right) ; \\
& \frac{\eta}{1-h_{t}}=\lambda_{t} w_{t} ; \\
& \frac{\lambda_{t}}{R_{t}}=\beta E_{t}\left(\frac{\lambda_{t+1}}{\pi_{t+1}}\right),
\end{aligned}
$$

where $\lambda_{t}$ is the Lagrangian multiplier associated with the budget constraint and $m_{t}=M_{t} / p_{t}, w_{t}=W_{t} / p_{t}, \pi_{t+1}=$ $p_{t+1} / p_{t}$, are real money balances, real wages, and the gross inflation rate, respectively. Equation (7) is the money demand equation (see Eq. (A.2) in Appendix A).

\subsection{Production sector}

\subsubsection{Entrepreneurs}

As in Bernanke et al. (1999), entrepreneurs manage firms that produce wholesale goods and borrow to finance the capital used in the production process. Entrepreneurs are risk neutral and have a finite expected horizon for planning purposes. The probability that an entrepreneur will survive until the next period is $v$, so his expected lifetime is

7 We assume that $R_{t}$ equals the rate of return on government bonds. 
$1 /(1-v)$. This assumption ensures that entrepreneurial net worth (the firm equity) will never be enough to fully finance the new capital acquisitions. Entrepreneurs issue debt contracts to finance their desired capital stock in excess of net worth.

At the end of each period, entrepreneurs purchase capital, $k_{t+1}$, that will be used in the next period at the real price $q_{t}$. Thus, the cost of the purchased capital is $q_{t} k_{t+1}$. The capital acquisition is financed partly by their net worth, $n_{t+1}$, and by borrowing, $q_{t} k_{t+1}-n_{t+1}$, from a financial intermediary. This intermediary obtains its funds from household deposits and faces an opportunity cost of funds equal to $R_{t}$, the economy's nominal risk-free rate of return between $t$ and $t+1$.

The entrepreneurs' demand for capital depends on the expected marginal return and the expected marginal external financing cost at $t+1, E_{t} f_{t+1}$, which equals the expected real interest rate on external (borrowed) funds. Consequently, the optimal entrepreneurs' capital demand guarantees that

$$
E_{t} f_{t+1}=E_{t}\left[\frac{z_{t+1}+(1-\delta) q_{t+1}}{q_{t}}\right],
$$

where $\delta$ is the capital depreciation rate, while the expected marginal return of capital is given by the right-hand-side terms in (10), in which $z_{t+1}$ is the marginal productivity of capital at $t+1$ and $(1-\delta) q_{t+1}$ is the value of one unit of capital used in $t+1$.

Bernanke et al. (1999) assume the existence of an agency problem that makes external finance more expensive than internal funds. The entrepreneurs costlessly observe their output, which is subject to a random outcome. The financial intermediaries incur an auditing cost to observe the output. After observing their project outcome, entrepreneurs decide whether to repay their debt or to default. If they default, the financial intermediaries audit the loan and recover the project outcome, less monitoring costs.

Bernanke et al. (1999) solve a financial contract that maximizes the payoff to the entrepreneur, subject to the lender earning the required rate of return. Bernanke et al. show that-given parameter values associated with the cost of monitoring the borrower, characteristics of the distribution of entrepreneurial returns, and the expected life span of firms - their contract implies an external finance premium, $S(\cdot)$, that depends on the entrepreneur's leverage ratio. The underlying parameter values determine the elasticity of the external finance premium with respect to the firm leverage. ${ }^{8}$

Accordingly, the marginal external financing cost is equal to a gross premium for external funds plus the gross real opportunity costs equivalent to the risk-free interest rate. Thus, the demand for capital should satisfy the following optimality condition ${ }^{9}$ :

$$
E_{t} f_{t+1}=E_{t}\left[S(\cdot) R_{t} / \pi_{t+1}\right]
$$

where $E_{t}\left(R_{t} / \pi_{t+1}\right)$ is an expected real interest rate, and the external finance premium is given by

$$
S(\cdot)=S\left(\frac{n_{t+1}}{q_{t} k_{t+1}}\right),
$$

with $S^{\prime}(\cdot)<0$ and $S(1)=1$.

The external finance premium, $S(\cdot)$, depends on the size of the borrower's equity stake in a project (or, alternatively, the borrower's leverage ratio). As $n_{t+1} / q_{t} k_{t+1}$ falls, the borrower relies on uncollateralized borrowing (higher leverage) to a larger extent to fund the project. Since this increases the incentive to misreport the outcome of the project, the loan becomes riskier and the cost of borrowing rises. ${ }^{10}$

From the Eqs. (11) and (12), we derive the log-linearized equation for the external funds rate as:

$$
\hat{f}_{t+1}=\hat{R}_{t}-\hat{\pi}_{t+1}+\psi\left(\hat{q}_{t}+\hat{k}_{t+1}-\hat{n}_{t+1}\right),
$$

where $\psi$ represents the elasticity of the external finance premium with respect to a change in the leverage position of entrepreneurs.

\footnotetext{
8 For details, see Appendix A of Bernanke et al. (1999) or the appendix in Gertler et al. (2003).

9 For more details, see Bernanke et al. (1999), who derive an optimal contract between entrepreneurs and financial intermediaries under an asymmetric information problem.

10 When the riskiness of loans increases, the agency costs rise and the lender's expected losses increase. A higher external finance premium paid by successful entrepreneurs offsets these higher losses and ensures that there is no change to the return on deposits for households.
} 
Aggregate entrepreneurial net worth evolves according to

$$
n_{t+1}=v v_{t}+(1-v) g_{t},
$$

where $v_{t}$ denotes the net worth of surviving entrepreneurs net of borrowing costs carried over from the previous period, $1-v$ is the share of new entrepreneurs entering the economy, and $g_{t}$ is the transfer or "seed money" that newly entering entrepreneurs receive from entrepreneurs who die and depart from the scene. ${ }^{11} v_{t}$ is given by

$$
v_{t}=\left[f_{t} q_{t-1} k_{t}-E_{t-1} f_{t}\left(q_{t-1} k_{t}-n_{t}\right)\right],
$$

where $f_{t}$ is the ex post real return on capital held in $t$, and $E_{t-1} f_{t}=E_{t-1}\left[S(\cdot) R_{t-1} / \pi_{t}\right]$ is the cost of borrowing (the real interest rate implied by the loan contract signed in time $t-1)$. Earnings from operations in this period become next period's net worth. In our formulation, borrowers sign a debt contract that specifies a nominal interest rate. ${ }^{12}$ The loan repayment (in real terms) will then depend on the ex post real interest rate (see Eq. (C.16) in Appendix C). An unanticipated increase (decrease) in inflation will reduce (increase) the real cost of debt repayment and, therefore, will increase (decrease) the entrepreneurial net worth.

To produce output $y_{t}$, the entrepreneurs use $k_{t}$ units of capital and $h_{t}$ units of labor following a constant-returnsto-scale technology:

$$
y_{t} \leqslant k_{t}^{\alpha}\left(A_{t} h_{t}\right)^{1-\alpha}, \quad \alpha \in(0,1),
$$

where $A_{t}$ is a technology shock common to all entrepreneurs. This follows a stationary first-order autoregressive process:

$$
\log A_{t}=\left(1-\rho_{A}\right) \log (A)+\rho_{A} \log \left(A_{t-1}\right)+\varepsilon_{A t},
$$

where $\rho_{A} \in(-1,1), A>0$ is a constant, and $\varepsilon_{A t}$ is normally distributed with zero mean and standard deviation $\sigma_{A}$.

Each entrepreneur sells its output, $y_{t}$, on a perfect competitive market for a price that equals its nominal marginal cost. The entrepreneur maximizes profits by choosing $k_{t}$ and $h_{t}$ subject to the production function (16). The first-order conditions for this optimization problem are:

$$
\begin{aligned}
& z_{t}=\alpha \xi_{t} \frac{y_{t}}{k_{t}} ; \\
& w_{t}=(1-\alpha) \xi_{t} \frac{y_{t}}{h_{t}} ; \\
& y_{t}=k_{t}^{\alpha}\left(A_{t} h_{t}\right)^{1-\alpha},
\end{aligned}
$$

where $\xi_{t}>0$ is the Lagrangian multiplier associated with the production function (16) and denotes the real marginal cost; $w_{t}$ is the real wage; and $z_{t}$ is the real marginal productivity of capital. ${ }^{13}$

\subsubsection{Capital producers}

Capital producers use a linear technology, which is subject to an investment-specific shock, $x_{t}$, to produce capital goods, sold at the end of period $t$. They use a fraction of final goods purchased from retailers as investment goods, $i_{t}$, to produce efficient investment goods, $x_{t} i_{t}$, that are combined with the existing capital stock to produce new capital goods, $k_{t+1} \cdot{ }^{14}$ The new capital goods replace depreciated capital and add to the capital stock. The disturbance $x_{t}$ is a shock to the marginal efficiency of investment (as in Greenwood et al., 1988). ${ }^{15}$ Since $i_{t}$ is expressed in consumption units, $x_{t}$ determines the amount of capital in efficiency units that can be purchased for one unit of consumption. Capital producers are also subject to quadratic capital adjustment costs specified as $\frac{\chi}{2}\left(\frac{i_{t}}{k_{t}}-\delta\right)^{2} k_{t}$.

\footnotetext{
11 The parameter $v$ will affect the persistence of changes in net worth.

12 In Bernanke et al. (1999), the contract is specified in terms of the real interest rate.

13 We assume that entrepreneurial consumption is small and it drops out of the model.

14 This setup follows Bernanke et al. (1999) and assumes that capital producers rent the capital stock from entrepreneurs and use it to produce new capital. Since this takes place within the period we assume that the rental rate is zero.

15 Greenwood et al. (2000) find that investment-specific technological progress is a source of about 30 percent of output fluctuations. They point to the negative co-movement of the relative price of new capital and equipment investment as motivation for the use of this type of shock.
} 
Capital producers' optimization problem, in real terms, consists of choosing the quantity of investment, $i_{t}$, to maximize their profits, so that:

$$
\max _{i_{t}} E_{t}\left[q_{t} x_{t} i_{t}-i_{t}-\frac{\chi}{2}\left(\frac{i_{t}}{k_{t}}-\delta\right)^{2} k_{t}\right] .
$$

Thus, the optimal condition is

$$
E_{t}\left[q_{t} x_{t}-1-\chi\left(\frac{i_{t}}{k_{t}}-\delta\right)\right]=0,
$$

which is the standard Tobin's $Q$ equation that relates the price of capital to the marginal adjustment costs. Capital adjustment costs slow down the response of investment to different shocks, which directly affects the price of capital. In the absence of capital adjustment costs, the capital price, $q_{t}$, is constant and equal to 1 . Therefore, capital adjustment costs allow the price of capital to vary, which contributes to volatility of entrepreneurial net worth.

The quantity and price of capital are determined in the market for capital. The entrepreneurial demand curve for capital is determined by Eqs. (11) and (18), while the supply of capital is given by Eq. (22).

The aggregate capital stock evolves according to

$$
k_{t+1}=x_{t} i_{t}+(1-\delta) k_{t},
$$

where $\delta$ is the capital depreciation rate, and the shock $x_{t}$ follows the first-order autoregressive process:

$$
\log \left(x_{t}\right)=\rho_{x} \log \left(x_{t-1}\right)+\varepsilon_{x t},
$$

where $\rho_{x} \in(-1,1)$ is an autoregressive coefficient, and $\varepsilon_{x t}$ is normally distributed with mean zero and standard deviation $\sigma_{x}$.

\subsubsection{Retailers}

The retail sector is used only to introduce nominal rigidity into this economy. Retailers purchase the wholesale goods from entrepreneurs at a price equal to the entrepreneurs' nominal marginal cost, and differentiate them at no cost. They then sell these differentiated retail goods in a monopolistically competitive market. Following Calvo (1983) and Yun (1996), we assume that each retailer cannot reoptimize its selling price unless it receives a random signal. The constant probability of receiving such a signal is $(1-\phi)$. Thus, each retailer $j$ sets the price, $\tilde{p}_{t}(j)$, that maximizes the expected profit for $l$ periods. Thus, $l=1 /(1-\phi)$ is the average length of time a price remains unchanged. However, with probability $\phi$, the retailer $j$ must charge the price that was in effect in the preceding period indexed by the steadystate gross rate of inflation, $\pi$. At time $t$, if the retailer $j$ receives the signal to reoptimize, it chooses prices $\tilde{p}_{t}(j)$ that maximizes its discount, expected real total profit over the intervals during which its price remains fixed. The retailer's optimization problem is

$$
\max _{\left\{\tilde{p}_{t}(j)\right\}} E_{0}\left[\sum_{l=0}^{\infty}(\beta \phi)^{l} \lambda_{t+l} \Omega_{t+l}(j) / p_{t+l}\right],
$$

subject to the demand function ${ }^{16}$

$$
y_{t+l}(j)=\left(\frac{\tilde{p}_{t}(j)}{p_{t+l}}\right)^{-\theta} y_{t+l},
$$

where the retailer's nominal profit function is

$$
\Omega_{t+l}(j)=\left(\pi^{l} \tilde{p}_{t}(j)-p_{t+l} \xi_{t+l}\right) y_{t+l}(j) .
$$

The first-order condition for $\tilde{p}_{t}(j)$ is

\footnotetext{
16 This demand function is derived from the definition of aggregate demand as the composite of individual final output (retail) goods and the corresponding price index in the monopolistic competition framework, as follows: $y_{t+l}=\left(\int_{0}^{1} y_{t+l}(j)^{\frac{\theta-1}{\theta}} \mathrm{d} j\right)^{\frac{\theta}{\theta-1}}$ and $p_{t+l}=\left(\int_{0}^{1} p_{t+l}(j)^{1-\theta} \mathrm{d} j\right)^{\frac{1}{1-\theta}}$, where $y_{t+l}(j)$ and $p_{t+l}(j)$ are the demand and price faced by each individual retailer $j \in(0,1)$.
} 


$$
\tilde{p}_{t}(j)=\frac{\theta}{\theta-1} \frac{E_{t} \sum_{l=0}^{\infty}(\beta \phi)^{l} \lambda_{t+l} y_{t+l}(j) \xi_{t+l}}{E_{t} \sum_{l=0}^{\infty}(\beta \phi)^{l} \lambda_{t+l} y_{t+l}(j) \pi^{l} / p_{t+l}} .
$$

The aggregate price is

$$
p_{t}^{1-\theta}=\phi\left(\pi p_{t-1}\right)^{1-\theta}+(1-\phi) \tilde{p}_{t}^{1-\theta} .
$$

These equations lead to the following New Keynesian Phillips curve:

$$
\hat{\pi}_{t}=\beta E_{t} \hat{\pi}_{t+1}+\frac{(1-\beta \phi)(1-\phi)}{\phi} \hat{\xi}_{t},
$$

where $\xi_{t}$ is the real marginal cost, and variables with hats are log deviations from the steady-state values (such as $\left.\hat{\pi}_{t}=\log \left(\pi_{t} / \pi\right)\right)$.

\subsection{Monetary authority}

Following Ireland (2003), we assume that the central bank adjusts the nominal interest rate, $R_{t}$, in response to deviations of inflation, $\pi_{t}$, output $y_{t}$, and the money-growth rate, $\mu_{t}=M_{t} / M_{t-1}$, from their steady-state values. Thus, the monetary policy rule evolves according to:

$$
\frac{R_{t}}{R}=\left(\frac{\pi_{t}}{\pi}\right)^{\varrho_{\pi}}\left(\frac{y_{t}}{y}\right)^{\varrho_{y}}\left(\frac{\mu_{t}}{\mu}\right)^{\varrho_{\mu}} \exp \left(\varepsilon_{R t}\right)
$$

where $R, \pi, y$, and $\mu$ are the steady-state values of $R_{t}, \pi_{t}, y_{t}$, and $\mu_{t}$, respectively, and $\varepsilon_{R t}$ is a monetary policy shock normally distributed with zero mean and standard deviation $\sigma_{R}$. The newly created money is transferred to households, so $T_{t}=M_{t}-M_{t-1}$.

We choose this policy rule to provide flexibility in the characterization of monetary policy. The policy coefficients, $\varrho_{\pi}, \varrho_{y}$, and $\varrho_{\mu}$, are chosen by the monetary authority. In this case, a unique equilibrium exists as long as the sum of $\varrho_{\pi}$ and $\varrho_{\mu}$ exceeds unity. This modified Taylor-type rule embeds the standard Taylor (1993) rule (when $\varrho_{\mu}=0$ ) where the monetary authority changes interest rates in response to inflation and output deviations. In addition, by reacting to money growth, the central bank is able to offset the negative effects of money-demand shocks on economic activity; see Dib (2006). Ireland (2003) estimates this policy rule for the same sample and finds evidence that the coefficient on money growth is positive and statistically significant. ${ }^{17}$

Since the parameters in this rule are estimated, we let the data decide upon the best characterization of monetary policy over the 1979 to 2004 period. Estimating this rule is important for our exercise, because allowing for a stronger output-stabilizing response of monetary policy may affect our conclusions regarding the importance of the financial accelerator.

\subsection{Symmetric equilibrium}

In the symmetric equilibrium, all entrepreneurs are identical, so they make the same decision. In this economy, the symmetric equilibrium consists of an allocation $\left\{y_{t}, c_{t}, m_{t}, i_{t}, h_{t}, k_{t}, n_{t}\right\}$ and a sequence of prices and co-state variables $\left\{w_{t}, z_{t}, R_{t}, f_{t}, q_{t}, \lambda_{t}, \xi_{t}\right\}$ that satisfy the optimality conditions of households, capital producers, entrepreneurs, and retailers; the money-supply rule; and the stochastic processes for preferences, money demand, productivity, investment, and monetary policy shocks (see Appendix A).

Taking a log-linear approximation of the equilibrium system around steady-state values, and using Blanchard and Kahn's (1980) procedure, yields a state-space solution of the form:

$$
\begin{aligned}
& \hat{\mathbf{s}}_{t+1}=\Phi_{1} \hat{\mathbf{s}}_{t}+\Phi_{2} \varepsilon_{t+1} ; \\
& \hat{\mathbf{d}}_{t}=\Phi_{3} \hat{\mathbf{s}}_{t},
\end{aligned}
$$

where the state variable vector, $\hat{\mathbf{s}}_{t}$, includes predetermined and exogenous variables; $\hat{\mathbf{d}}_{t}$ is the vector of control variables; and the vector $\varepsilon_{t}$ contains the random innovations. The coefficient matrices, $\Phi_{1}, \Phi_{2}$, and $\Phi_{3}$, have elements

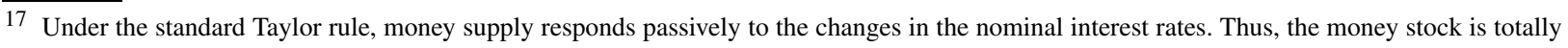
determined by the money demand.
} 
that depend on the structural parameters of the model. Therefore, the state-space solution, (32) and (33), is used to estimate and simulate the model.

\section{Data and estimation strategy}

As in previous studies that have estimated DSGE models using a maximum-likelihood procedure, we set some parameters prior to estimation because the data series used contain little information about them. ${ }^{18}$ Thus, the discount rate $\beta$ is set equal to 0.9928 implying an annual steady-state real interest rate of $2.93 \%$, which equals to the average of real interest rate over our estimation sample. The parameter $\eta$, denoting the weight on leisure in the utility function, is set equal to 1.315 , so that the household spends around one third of its time in market activities. The parameter $\theta$ that measures the degree of retailers' monopoly power, is set equal to 6, implying a steady-state price markup of $20 \%$, a common value used in the literature. The depreciation rate, $\delta$, is assigned the commonly used values of 0.025 . The constant associated with money demand, $b$, is set to 0.062 , to ensure that the steady-state ratio of real balances to consumption is close to its historical value. The steady-state gross inflation rate, $\pi$, is equal to 1.0079 , which matches the historical average over the estimation sample.

The steady-state external finance premium, $S$, is set to 1.0075 , corresponding to an annual risk spread of 300 basis points, equal to the sample average spread between the business prime lending rate and the three-month Treasury bill rate. Following Bernanke et al. (1999), we set the steady-state ratio of capital to net worth, $k / n$, equal to 2 . This implies a firm leverage ratio, defined as the ratio of debt to assets, of 0.5. Finally, we also use Bernanke et al. (1999) value of 0.9728 for the survival rate of entrepreneurs, $v$, implying an expected working life for entrepreneurs of 36 years. Table 1 reports the calibration values for the non-estimated parameters.

The remaining non-calibrated parameters, including the elasticity of the external finance premium with respect to the firm's leverage ratio, $\psi$, are estimated using a maximum-likelihood procedure. This method applies a Kalman filter to the model's state-space form to generate series for the innovations used to evaluate the likelihood function for the sample. Because the solution is a state-space econometric model, driven by five innovations in $\varepsilon_{t}$, the structural parameters embedded in $\Phi_{1}, \Phi_{2}$, and $\Phi_{3}$ can be estimated by a maximum-likelihood procedure using data on five variables: output, investment, real balances, the short-term nominal interest rate, and inflation. ${ }^{19}$ We use data on investment because financial frictions exert an influence directly on investment behavior. In addition, investment data are required to identify and precisely estimate the capital adjustment cost and capital share parameters.

Using quarterly US data from 1979Q3 through 2004Q3, we estimate two versions of the model. ${ }^{20}$ The first is a model with an active financial accelerator mechanism (FA model). The second is the same model, but with the financial accelerator mechanism turned off (EstNoFA model). In this model, the parameter $\psi$ is constrained to equal zero. $^{21}$ See the linearized equations in Appendix $\mathrm{C}$ for more details.

\begin{tabular}{lll}
$\begin{array}{l}\text { Table } 1 \\
\text { Parameter calibration }\end{array}$ & \\
\hline Parameters & Definition & Values \\
\hline$\beta$ & discount factor & 0.9928 \\
$\eta$ & weight on leisure in the utility function & 1.315 \\
$\theta$ & intermediate-goods elasticity of substitution & 6 \\
$\delta$ & capital depreciation rate & 0.025 \\
$b$ & constant associated with money demand shock & 0.062 \\
$\pi$ & gross steady-state inflation rate & 1.0079 \\
$\nu$ & survival rate of entrepreneurs & 0.9728 \\
$S$ & gross steady-state risk premium & 1.0075 \\
$k / n$ & steady-state ratio of capital to net worth & 2 \\
\hline
\end{tabular}

\footnotetext{
18 This estimation method is used by Bouakez et al. (2005), Dib (2003, 2006), Ireland (2003), and several others.

19 This method is described in Hamilton (1994, Chapter 13).

20 This period corresponds to the Volcker-Greenspan era at the Federal Reserve, which is often characterized as a period of relatively constant monetary policy. We can thus avoid the indeterminacy problems often found for models estimated with pre-1979 data.

21 Both models are estimated with the same steady-state external finance premium. Therefore, steady-state equilibrium values of the variables are the same in the two estimated models.
} 
In the US data, output is measured by real GDP excluding government expenditures, since there is no government spending in the model. Investment is measured by real gross private domestic investment. Real money balances are measured by dividing the base money stock, M0, by the GDP deflator. ${ }^{22}$ The inflation rate is measured by changes in the GDP implicit price deflator, while the short-term nominal interest rate is measured by the rate on three-month treasury bills. Data on output, real balances, and investment are expressed in per capita terms using the civilian population aged 16 and over. All the series are HP-filtered before the estimation, including inflation and interest rates, because they exhibit a small downward trend over the sample.

\section{Empirical results}

\subsection{Parameter estimates}

Table 2 displays the maximum-likelihood estimates of the structural parameters, with their standard errors, for the FA and EstNoFA models. The estimated value of the key parameter of the financial accelerator mechanism, $\psi$, the elasticity of the external finance premium with respect to firm leverage is 0.042 and statistically different from zero at a $1 \%$ significance level. Note that this estimated value is not statistically different from 0.05 , a value often used to calibrate this parameter (see for example, Bernanke et al., 1999; Bernanke and Gertler, 2000; Fukunaga, 2002; and Gilchrist, 2004). ${ }^{23}$ Meier and Müller (2006) report a higher estimated value of 0.067 for this parameter, but find it to be statistically insignificant.

The capital adjustment cost parameter, $\chi$, is estimated at 0.59 in the FA model, and at 0.49 in the EstNoFA model, with a standard errors of 0.17 and 0.13 , respectively. Thus, both estimates are statistically significant and not statistically different across models. These estimates are larger than the 0.25 value for the capital adjustment cost parameter used by Bernanke et al. (1999) and others. ${ }^{24}$ As mentioned earlier, $\chi$ has an important impact on the financialaccelerator mechanism. If capital adjustment costs are high, the capital price responds to shocks to a greater extent, with direct effects on the net worth of firms (through capital gains and losses) and therefore on the cost of external

Table 2

Maximum-likelihood estimates: 1979Q3 to 2004Q3

\begin{tabular}{llllll}
\hline Parameters & \multicolumn{2}{l}{ FA model } & & \multicolumn{2}{l}{ EstNoFA model } \\
\cline { 2 - 3 } \cline { 5 - 6 } & Estimates & Std. errors & & Estimates & Std. errors \\
\hline$\psi$ & 0.0420 & 0.0137 & - & - \\
$\chi$ & 0.5882 & 0.1742 & 0.4913 & 0.1293 \\
$\alpha$ & 0.3384 & 0.0259 & 0.3741 & 0.0363 \\
$\gamma$ & 0.0598 & 0.0039 & & 0.0857 & 0.0211 \\
$\phi$ & 0.7418 & 0.0118 & & 0.7674 & 0.0408 \\
$\varrho_{\pi}$ & 1.4059 & 0.0788 & 1.3557 & 0.2098 \\
$\varrho_{y}$ & 0.2947 & 0.0690 & 0.1379 & 0.0647 \\
$\varrho_{\mu}$ & 0.6532 & 0.0783 & 0.7212 & 0.2135 \\
$\sigma_{R}$ & 0.0058 & 0.0003 & 0.0061 & 0.0013 \\
$\rho_{A}$ & 0.7625 & 0.0262 & 0.7745 & 0.0561 \\
$\sigma_{A}$ & 0.0096 & 0.0015 & 0.0128 & 0.0067 \\
$\rho_{b}$ & 0.7206 & 0.0242 & 0.5547 & 0.0164 \\
$\sigma_{b}$ & 0.0103 & 0.0008 & 0.0135 & 0.0028 \\
$\rho_{z}$ & 0.6156 & 0.0194 & 0.7549 & 0.0380 \\
$\sigma_{z}$ & 0.0073 & 0.0007 & 0.0083 & 0.0012 \\
$\rho_{x}$ & 0.6562 & 0.0161 & 0.7930 & 0.0476 \\
$\sigma_{x}$ & 0.0331 & 0.0039 & 0.0240 & 0.0055 \\
$L L$ & 1911.2 & & & \\
\hline
\end{tabular}

\footnotetext{
22 We use the monetary base as our measure of money to keep it conceptually distinct from the household deposits that fund the capital investment in the model. Ireland (2003) uses M2 as the measure of money.

23 Bernanke et al. (1999) calibrate $\psi=0.05$ based on realistic values for monitoring costs and bankruptcy rates.

24 Bernanke et al. (1999) argue that a reasonable value for $\chi$ lies within a range from 0 to 0.5 .
} 
financing. Of course, high adjustment costs also make investment more expensive and less responsive to shocks. Meier and Müller (2006) report an estimate of 0.65 , close to that in our FA model.

The estimates of $\alpha$, the share of capital in the production function, are similar to those often assumed in the literature. They are 0.34 in the model and 0.37 in the FA and EstNOFA models, respectively. The estimates of $\gamma$, the constant elasticity of substitution between consumption and real balances, are statistically significant and estimated at 0.06 and 0.08 in the FA and EstNoFA models, respectively. These estimates are larger than those estimated in Ireland (2003) for the post-1979 period. The estimate of the sticky price parameter, $\phi$, which indicates the probability that prices remain unchanged for the next period, is around 0.75 in both estimated models. This implies an expected price duration of about four quarters.

We next examine the estimates of monetary policy parameters. In both models, the estimated values of $\varrho_{\pi}, \varrho_{y}$, and $\varrho_{\mu}$, the coefficients that measure the responses of monetary policy to deviations of inflation, output and money growth, are positive and statistically significant. ${ }^{25}$ In the FA model, the estimated values of $\varrho_{\pi}, \varrho_{y}$, and $\varrho_{\mu}$ are about 1.41, 0.29, and 0.65, respectively. In the EstNOFA model, the estimate of $\varrho_{\pi}$ and $\varrho_{y}$ are smaller, while the one of $\varrho_{\mu}$ is larger. In particular, they are estimated at $1.36,0.14$, and 0.72 , respectively. Only the estimates of $\varrho_{y}$ are statistically different across the two models. The estimates of $\sigma_{R}$, the standard deviation of monetary policy shock, are similar in the two estimated models, with estimated values close to 0.006 .

The larger estimated coefficient for $\varrho_{y}$ in the FA model is a sign that the financial accelerator is playing an important role. The presence of the financial accelerator leads to an amplification and propagation of the impacts of the shocks on output, since investment is more volatile. Thus, the monetary authority needs to respond more aggressively to changes in this variable to stabilize the economy than it would if there were no financial accelerator.

The investment-efficiency shock stands out in both models as having the largest volatility. The estimates of $\sigma_{x}$, the standard deviation of investment-efficiency shocks, is 0.033 in the FA model, larger than the estimate of 0.024 in the EstNoFA model. However, this shock is less persistent in the FA model, with its autoregressive coefficient, $\rho_{x}$, estimated at 0.66 , compared to 0.79 in the EstNoFA model. We therefore find that large investment shocks are important for the empirical model to explain the co-movement of investment and the other variables in the post-1979 data. Ireland's (2003) findings are similar, and he argues that large investment shocks are required for the model to explain the investment boom of the 1990s.

There is not a notable difference in the estimated persistence of the remaining shocks across the models. The estimates of the shocks' autoregressive coefficients show that all the shocks are moderately persistent, with their autoregressive coefficients lying within a range from 0.62 to 0.76 , in the FA model, and from 0.55 to 0.77 in the EstNoFA model. In fact, all of the shocks, except for the money demand shock, are less persistent in the FA model, possibly because of the added propagation effects from net worth that the accelerator mechanism brings to the model. The estimates of standard deviations of the shocks are quite similar in both models.

Do the dynamic effects associated with fluctuations in net worth and the risk premium allow the FA model to better capture the co-movement in the data? We use the likelihood-ratio test to test the restriction imposed by the EstNoFA model $(\psi=0)$ against the model with the financial accelerator (FA model). Let $L^{u}$ and $L^{c}$ denote the maximum values of the log-likelihood function for the unconstrained (FA) and constrained (EstNoFA) models, respectively. The likelihood-ratio statistic $-2\left(L^{c}-L^{u}\right)$ has a $\chi^{2}$ distribution with one degree of freedom under the null hypothesis that the EstNoFA is valid. The value of $L^{u}$ is 1911.2 and that of $L^{c}$ is 1904.3, giving a test statistic of 13.8. The 1 percent critical value for a $\chi^{2}(1)$ is 6.64 . Therefore, the likelihood-ratio test easily rejects the restriction of the EstNoFA model in favor of the model that includes a financial accelerator. Thus, the introduction of the accelerator mechanism improves the model's ability to fit the data. In the remaining sections we investigate what features of the data are better captured by the FA model.

\subsection{Impulse responses}

To illustrate the different model dynamics implied by the financial accelerator we plot the impulse responses of key macroeconomic variables to the structural shocks in three models: (1) the FA model, (2) the EstNoFA model, and (3) the FA model with the accelerator mechanism turned off by setting $\psi=0$, but keeping all of the other parameter

$\overline{25}$ Unlike Ireland (2003), we assume that monetary authority responds to money base fluctuations rather then the changes in M2 stocks. 

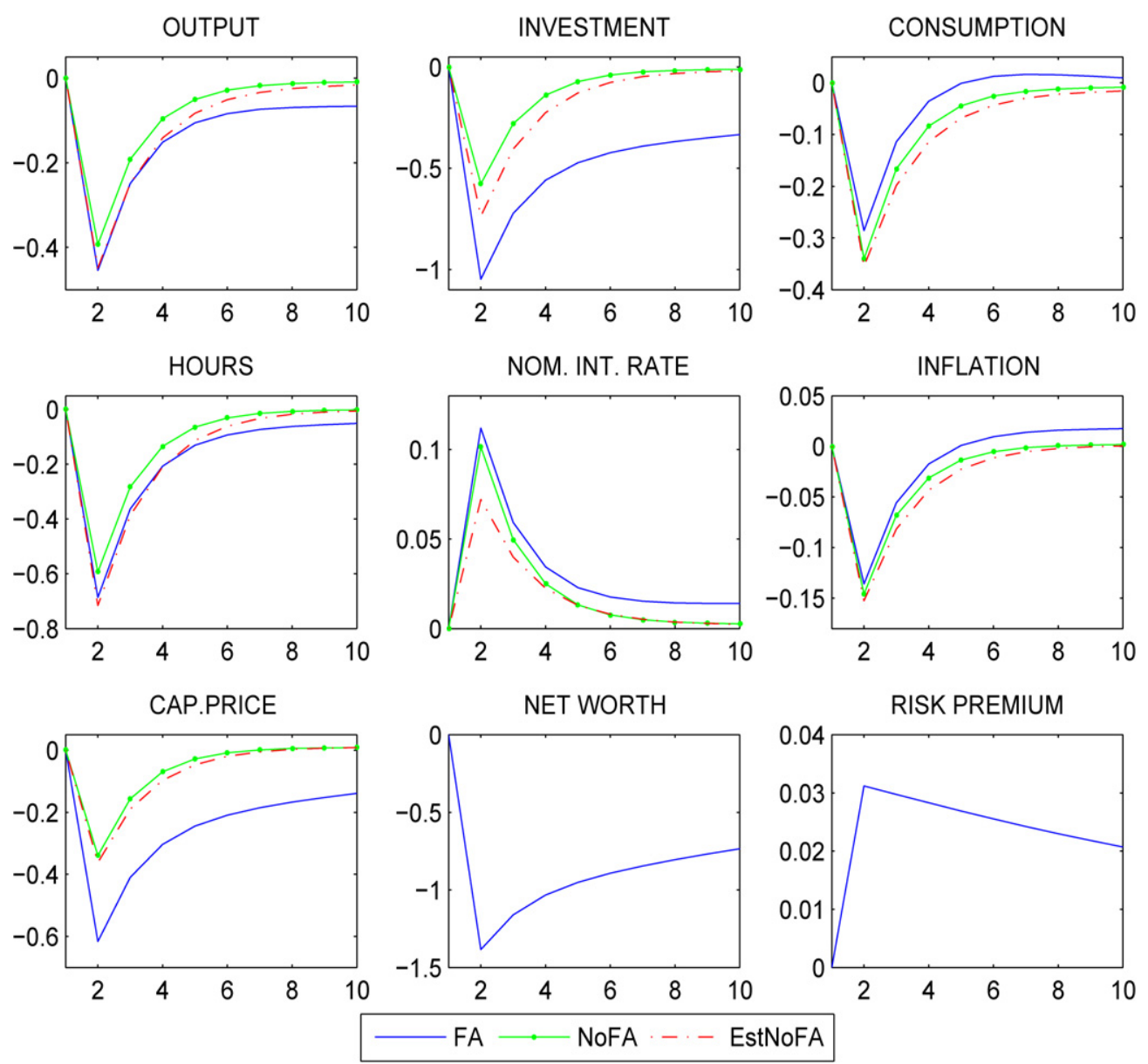

Note: The responses are percentage deviations of a variable from its steady-state value.

Fig. 1. The economy's responses to a tightening monetary policy shock.

estimates from the FA model (NoFA model, hereafter). Figures 1 to 5 display the impulse responses to a $1 \%$ positive shock to monetary policy, technology, money demand, preferences, and the investment efficiency. Each variable's response is expressed as the percentage deviation from its steady-state level.

Figure 1 plots the responses to a positive $1 \%$ monetary policy shock (tightening). Following this shock, the nominal interest rate rises and output, investment, consumption, hours, inflation fall sharply on impact. The basic mechanism of the financial accelerator is evident in the impulse responses. After a tightening in monetary policy, net worth falls, because of the declining return to capital and the higher real interest costs associated with existing debt (the debtdeflation effect). The external finance premium rises, reflecting the increase in firm leverage. The higher funding cost of purchasing new capital depresses the demand for it, and the expected price of capital persists below its steady-state value.

The presence of a financial accelerator mechanism implies a significant amplification and propagation of the monetary policy shock on investment and capital prices, as the responses of these variables in the FA model are almost double those in the NoFA model and persist for longer. These impulse responses show considerably more amplification of the response of investment than reported in Meier and Müller (2006). Despite the presence of the accelerator, however, the responses of output and hours in the FA model are very similar to those of the EstNoFA model, with the FA model generating slightly more persistent responses.

Figure 2 shows that, following a $1 \%$ positive technology shock, there is little impact of the financial accelerator on output. The components of output tell a different story. There is marginal amplification of consumption, but also a dampening of the investment response when the financial accelerator is present. Following the technology shock 

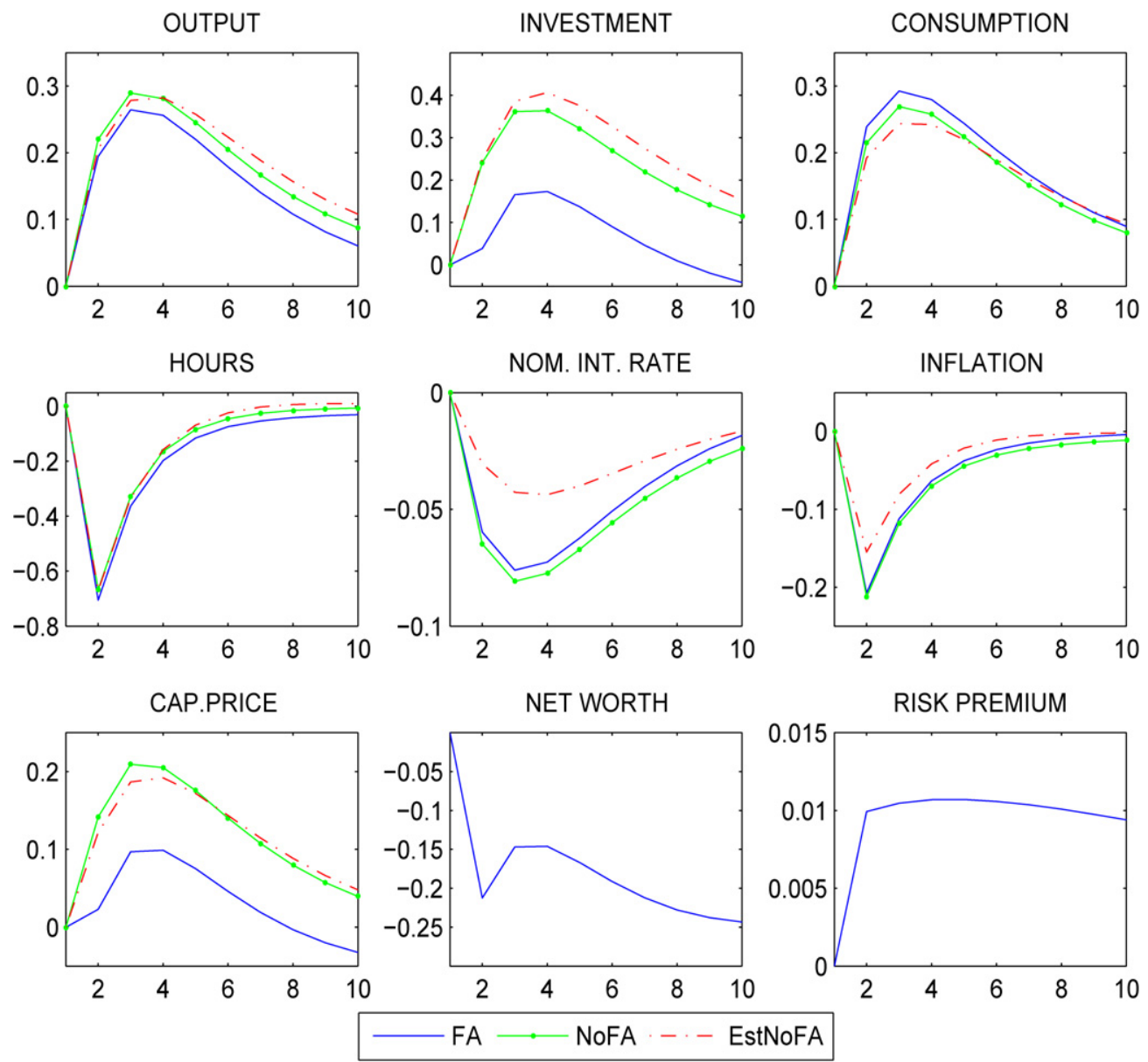

Note: The responses are percentage deviations of a variable from its steady-state value.

Fig. 2. The economy's responses to a positive technology shock.

nominal interest rates and inflation decrease. The decline in inflation increases the real cost of repaying existing debt, creating a debt-deflation effect, which pushes down net worth. ${ }^{26}$ Adding to this effect is the monetary authority who responds more aggressively to output fluctuations in the model with financial frictions making the decline in inflation more pronounced. Lower net worth increases the external finance premium, dampening the rise in the demand for capital. As a result, the response of investment and the price of capital to the technology shock are much smaller when the financial accelerator is present. ${ }^{27}$ As is often found in sticky-price models, hours worked decline after a positive technology shock. The decline in hours worked, however, is not very different in the models with and without a financial accelerator mechanism.

Figure 3 shows the impulse responses to a $1 \%$ positive money-demand shock. As the demand for real balances rises, consumption and savings fall, depressing output and investment. In addition, with less output being produced, but more liquidity expected in the economy, inflation rises. The monetary authority responds with higher interest rates and an increased supply of money, since the interest elasticity of money demand, $\gamma$, is small. In the FA model, there is much larger drop in investment and the price of capital owing to the accelerator effects. The lower returns to capital lead to a decrease in net worth and external finance premium rises.

\footnotetext{
26 The decline in net worth is very persistent, returning to its steady-state level after about 30 quarters.

27 When we simulate the FA model with either a real debt contract, i.e. without the debt deflation effect, or with a less aggressive monetary policy response to output fluctuations, $\varrho_{y}=0.14$ as estimated in the EstNoFA model, net worth increases and the external finance premium decreases following a positive technology shock.
} 

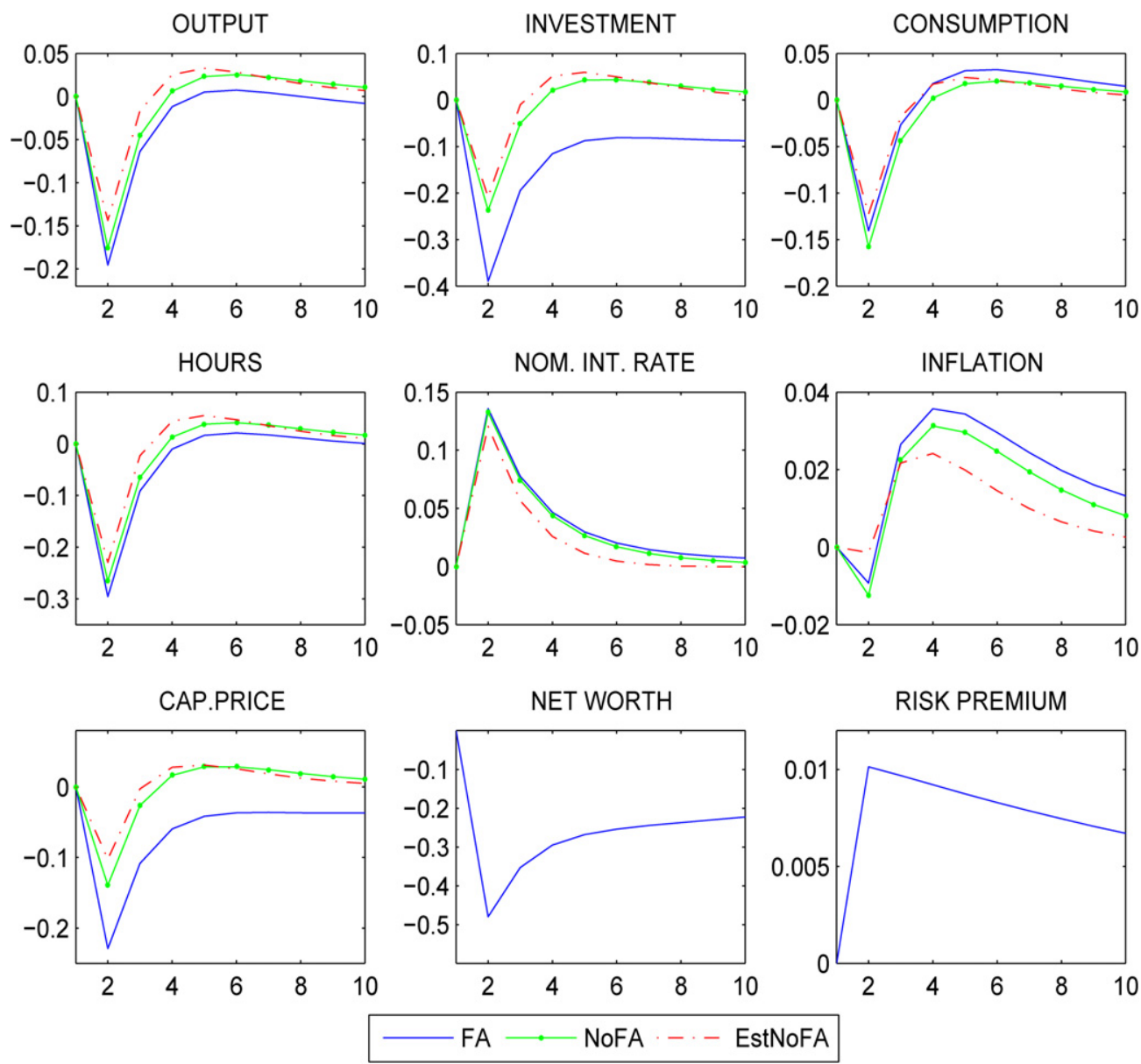

Note: The responses are percentage deviations of a variable from its steady-state value.

Fig. 3. The economy's responses to a positive money-demand shock.

Figure 4 shows the impulse responses to a $1 \%$ positive preference shock, which raises the marginal utility of consumption and therefore the opportunity cost of holding deposits (savings). As households divert deposits towards consumption, the return on deposits (the risk-free real interest rate) rises. The presence of the financial accelerator amplifies the decline in investment, but the responses of output and consumption are almost identical in the models with and without financial frictions. In the accelerator model, the rise in the real interest rate has a larger effect on investment, due to its negative impact on the firms' net worth.

Figure 5 shows the impulse responses to a $1 \%$ positive investment-efficiency shock. The investment shock is a positive shock to the marginal efficiency with which final (consumption) goods are turned into investment goods. In response to a positive investment-efficiency shock, the price of an efficiency unit of capital, $q_{t}$, falls. Output, investment and hours increase before returning gradually to their steady-states levels in the three models considered. In the FA model the response of real variables' to this shock are smaller than those from the NoFA and EstNoFA models and the decline in the price of capital is more pronounced. This is because, in the FA model, the replacement cost of existing capital falls, lowering the return on capital and hence net worth. The resulting rise in the external finance premium raises the cost of funding investment purchases, dampening the rise of investment. With less resources redeployed to purchase investment goods, the decline in consumption is less pronounced.

Overall, the presence of a financial accelerator mechanism, as proposed by Bernanke et al. (1999), significantly amplifies and propagates the impact of the demand-side shocks-monetary policy, money demand, and preference shocks - on investment and the price of capital. However, the impact of this mechanism on output and other real variables is marginal. On the other hand, the financial accelerator mechanism dampens (pushes down) the rise of output 

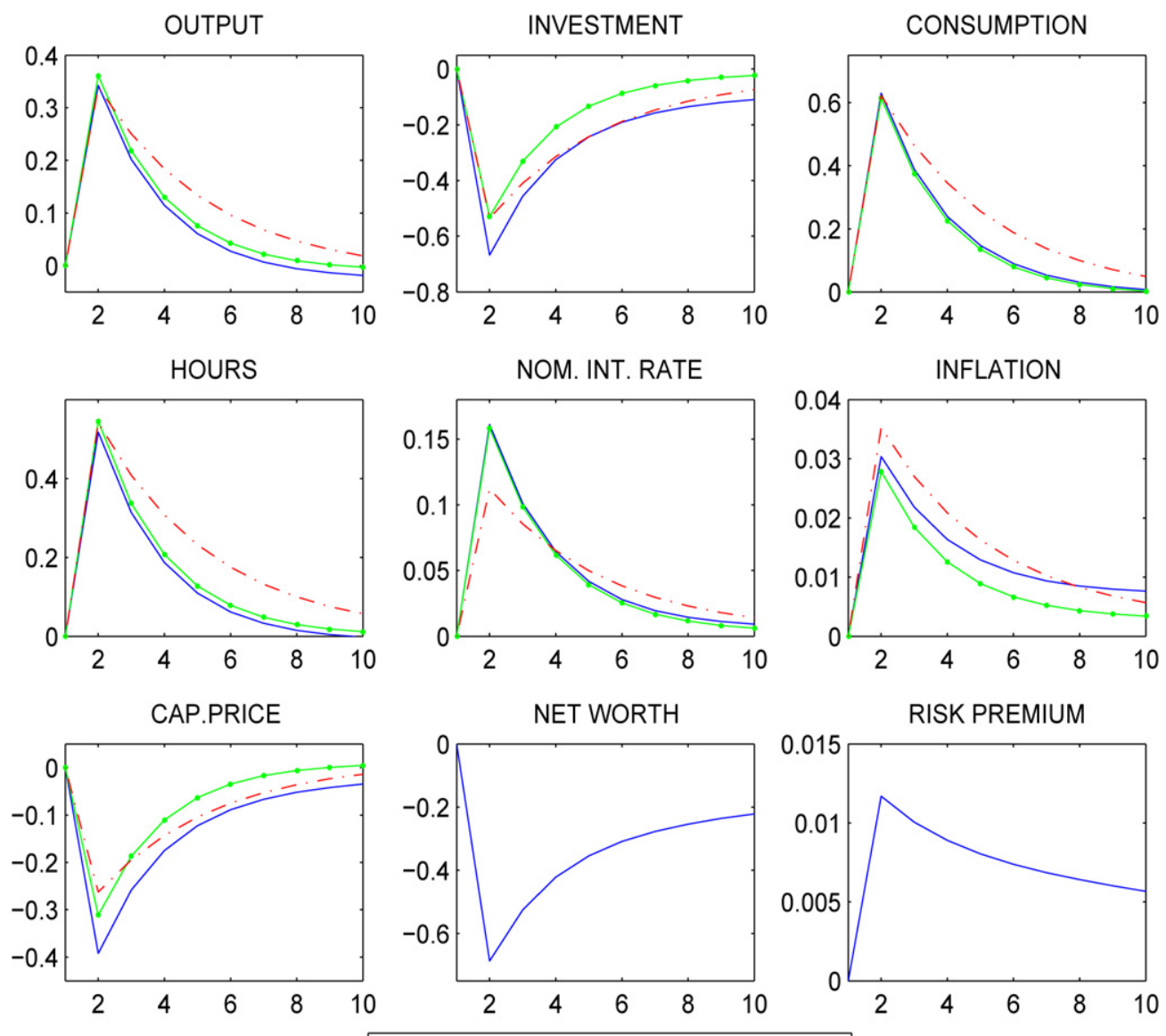

Note: The responses are percentage deviations of a variable from its steady-state value.

Fig. 4. The economy's responses to a positive preference shock.

and investment following positive supply-side shocks-technology and investment-efficiency shocks. The effect of the financial accelerator on output and investment fluctuations, therefore, depends on the nature of the shocks. These results are in line with Iacoviello (2005) who finds that nominal debt contracts lead the financial accelerator to dampen the effects of supply shocks.

\subsection{Volatility, autocorrelations, and cross-correlations}

To assess the contribution of the accelerator mechanism in our estimated model, we consider the model-implied volatilities (standard deviations), autocorrelations, and cross-correlations of the main variables of interest. Table 3 reports the standard deviations and relative volatilities of output, investment, consumption, real balances, the nominal interest rate, and inflation from the data, and for the three simulated models: FA, EstNoFA, and NoFA models. ${ }^{28}$ The standard deviations are expressed in percentage terms. The model-implied standard deviations and relative volatilities are calculated for different combinations of the shocks.

Column 2, in Table 3, displays standard deviations and relative volatilities of the actual data. Columns 3-5, however, report those simulated when all of the models' shocks are active. In the data, investment is about 5 times as volatile as output, while consumption is less volatile than output: the standard deviation of output is 1.04, investment is 5.61,

\footnotetext{
28 In the data, all series are HP-filtered before calculating their standard deviations as well as their unconditional autocorrelations and crosscorrelations.
} 

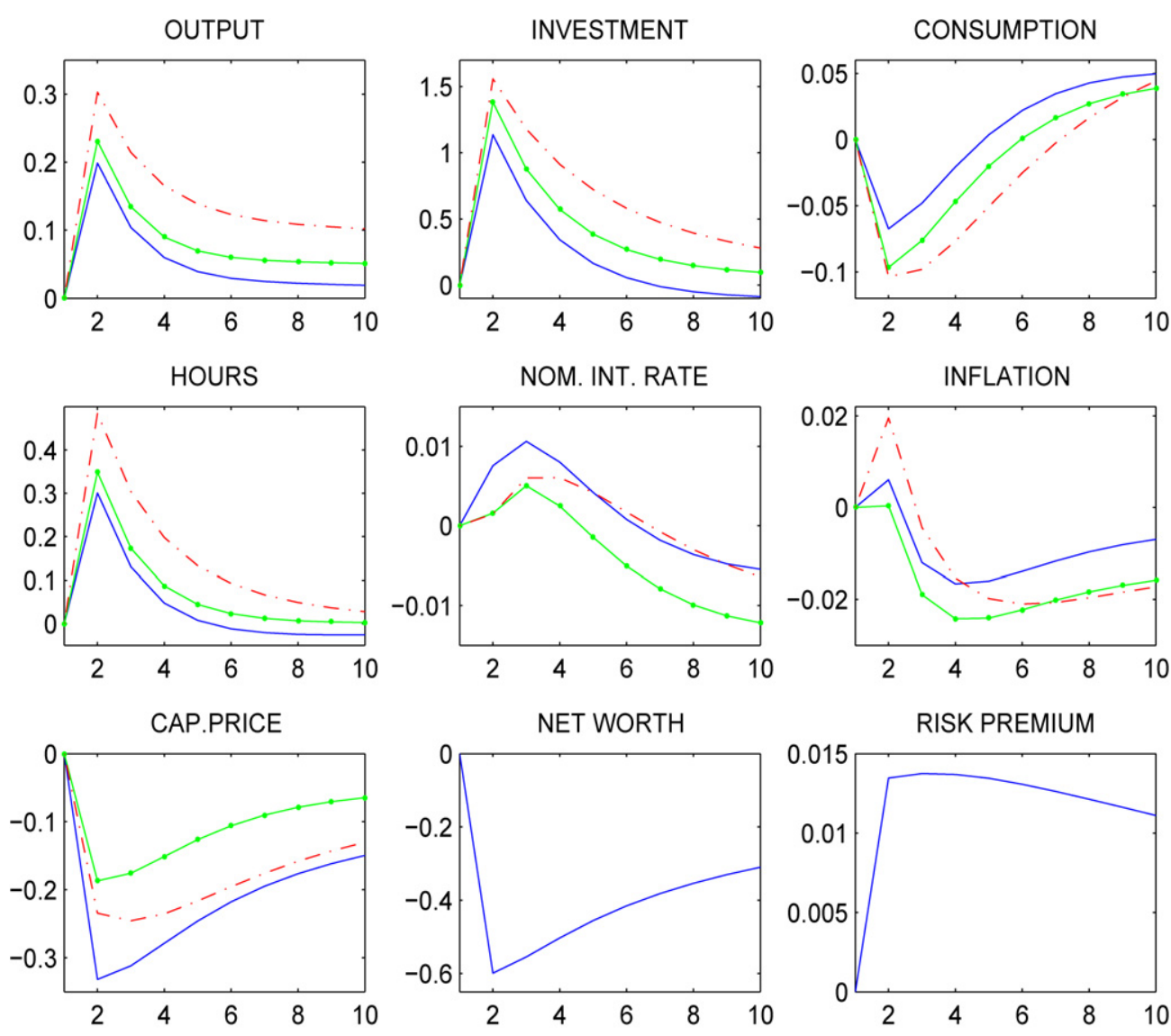

FA - - NoFA - - EstNoFA

Note: The responses are percentage deviations of a variable from its steady-state value.

Fig. 5. The economy's responses to a positive investment-efficiency shock.

while consumption is 0.72 . Real balances has a standard deviation of 1.52 . The short-term nominal interest rate and inflation are less volatile; their standard deviations are 0.31 and 0.21 , respectively.

The simulation results with all of the shocks show that, in the model where the accelerator is active, output volatility is close to that in the data. The model in which the accelerator is inactive overpredicts output volatility, however, a feature common in sticky-price models. The FA model underpredicts the volatility of investment and the NoFA models both overpredict it. However, the FA model generates the highest relative volatility of investment (4.34) and is closest to the value in the data (5.4). Despite generating a higher standard deviation of investment, the EstNoFA model only generates relative volatility of investment to output of slightly over half that in the data.

Conversely, the relative volatility of consumption implied by the FA model is higher than in the data. This is not a surprising result since investment spending in the model is funded by household savings. Increased savings volatility results in increased consumption volatility in the model. The EstNoFA model also overpredicts the relative volatility of consumption, but to a lesser degree.

The FA model is successful at matching the relative volatility of nominal interest rates. The EstNoFA model underpredicts the interest rate volatility. This is attributable, in part, to the more aggressive response of the monetary authorities to output deviations in the FA model. The EstNoFA model shows a slightly better match for the relative volatilities of inflation and real balances, but the difference with the FA model is relatively minor.

Columns 6-14, in Table 3, display the model-implied standard deviations and relative volatilities when considering different combinations of the shocks. When the models are simulated with only the demand shocks the volatility of investment in the FA model is double that of the NoFA model and a third higher than the EstNoFA model. Supply 
Table 3

Standard deviations and relative volatilities: data and models

\begin{tabular}{|c|c|c|c|c|c|c|c|c|c|c|c|c|c|}
\hline \multirow[t]{2}{*}{ Var. } & \multirow[t]{2}{*}{ Data } & \multicolumn{3}{|c|}{ All of the shocks } & \multicolumn{3}{|c|}{ Demand shocks } & \multicolumn{3}{|c|}{ Supply shocks } & \multicolumn{3}{|c|}{ No investment shocks } \\
\hline & & $\overline{\mathrm{FA}}$ & NoFA & EstNoFA & $\overline{\mathrm{FA}}$ & NoFA & EstNoFA & $\overline{\mathrm{FA}}$ & NoFA & EstNoFA & $\overline{\mathrm{FA}}$ & NoFA & EstNoFA \\
\hline \multicolumn{14}{|c|}{ A. Standard deviations (in \%) } \\
\hline$y_{t}$ & 1.04 & 1.14 & 1.62 & 2.08 & 0.59 & 0.47 & 0.58 & 0.98 & 1.15 & 2.00 & 0.80 & 0.77 & 1.03 \\
\hline$i_{t}$ & 5.61 & 4.95 & 6.22 & 6.34 & 1.54 & 0.69 & 0.94 & 4.71 & 6.18 & 6.27 & 1.61 & 1.03 & 1.52 \\
\hline$c_{t}$ & 0.72 & 1.15 & 1.34 & 1.76 & 0.67 & 0.63 & 0.84 & 0.94 & 1.18 & 1.54 & 0.91 & 0.85 & 1.12 \\
\hline$m_{t}$ & 1.52 & 1.93 & 2.60 & 2.88 & 1.06 & 0.93 & 0.79 & 1.61 & 2.43 & 2.77 & 1.61 & 1.54 & 1.69 \\
\hline$R_{t}$ & 0.31 & 0.31 & 0.40 & 0.33 & 0.26 & 0.23 & 0.24 & 0.18 & 0.33 & 0.22 & 0.30 & 0.29 & 0.27 \\
\hline$\pi_{t}$ & 0.21 & 0.31 & 0.43 & 0.35 & 0.15 & 0.12 & 0.13 & 0.27 & 0.41 & 0.32 & 0.28 & 0.29 & 0.27 \\
\hline \multicolumn{14}{|c|}{ B. Relative volatilities } \\
\hline$y_{t}$ & 1 & 1 & 1 & 1 & 1 & 1 & 1 & 1 & 1 & 1 & 1 & 1 & 1 \\
\hline$i_{t}$ & 5.40 & 4.34 & 3.84 & 3.05 & 2.61 & 1.47 & 1.62 & 4.81 & 5.37 & 3.13 & 2.01 & 1.34 & 1.48 \\
\hline$c_{t}$ & 0.69 & 1.01 & 0.82 & 0.84 & 1.13 & 1.34 & 1.45 & 0.96 & 1.02 & 0.77 & 1.14 & 1.10 & 1.09 \\
\hline$m_{t}$ & 1.46 & 1.68 & 1.60 & 1.38 & 1.79 & 1.97 & 1.36 & 1.64 & 2.11 & 1.38 & 2.01 & 2.00 & 1.64 \\
\hline$R_{t}$ & 0.30 & 0.27 & 0.25 & 0.16 & 0.44 & 0.49 & 0.41 & 0.18 & 0.29 & 0.11 & 0.37 & 0.38 & 0.27 \\
\hline$\pi_{t}$ & 0.20 & 0.27 & 0.26 & 0.17 & 0.25 & 0.26 & 0.26 & 0.28 & 0.36 & 0.16 & 0.35 & 0.38 & 0.26 \\
\hline
\end{tabular}


shocks account for most of the volatility in investment in all of the models considered. However, investment is less volatile in the FA model than in the NoFA model, illustrating the dampening effect on supply shocks. Finally, without the investment shock, the volatilities implied by the FA and EstNoFA are similar, with the FA model doing slightly better on the components of output and the EstNoFA model matching the output volatility.

Relative volatility of investment is higher in the FA model simulated with different combinations of the shocks. With supply shocks, the generated values in the FA and NoFA models are close to that observed in the data. When excluding investment shocks, however, relative volatility of output is much smaller, in particular in the models with no financial accelerator. Therefore, the presence of the financial accelerator and investment shocks are needed to improve sticky-price model's fit with output and investment volatilities.

Figure 6 plots the unconditional autocorrelations of the data and those of output, investment, consumption, nominal interest rates, inflation, and real balances generated by our models and from the data. In general, the model with the active FA mechanism does a better job at matching the autocorrelations shown in the data within a four-quarter horizon. The FA model shows considerably lower autocorrelation in output, investment, consumption and real balances than the other models. Of particular interest is that the FA model matches the autocorrelation in output very well. In addition, while investment in the FA model is less autocorrelated than in the data, it is quite close at the 3- and 4-quarter horizon. Both models generate too much autocorrelation in consumption, inflation and the nominal interest rate, but the FA model comes closer to the autocorrelation seen in the data in all three cases.

Figure 7 plots the unconditional cross-correlations of the data and those simulated in the three models. They are calculated between a given variable and lags of another variable. We report these cross-correlations for same variables as the other simulation exercises. Overall, the cross-correlations implied by the FA model correspond best to those
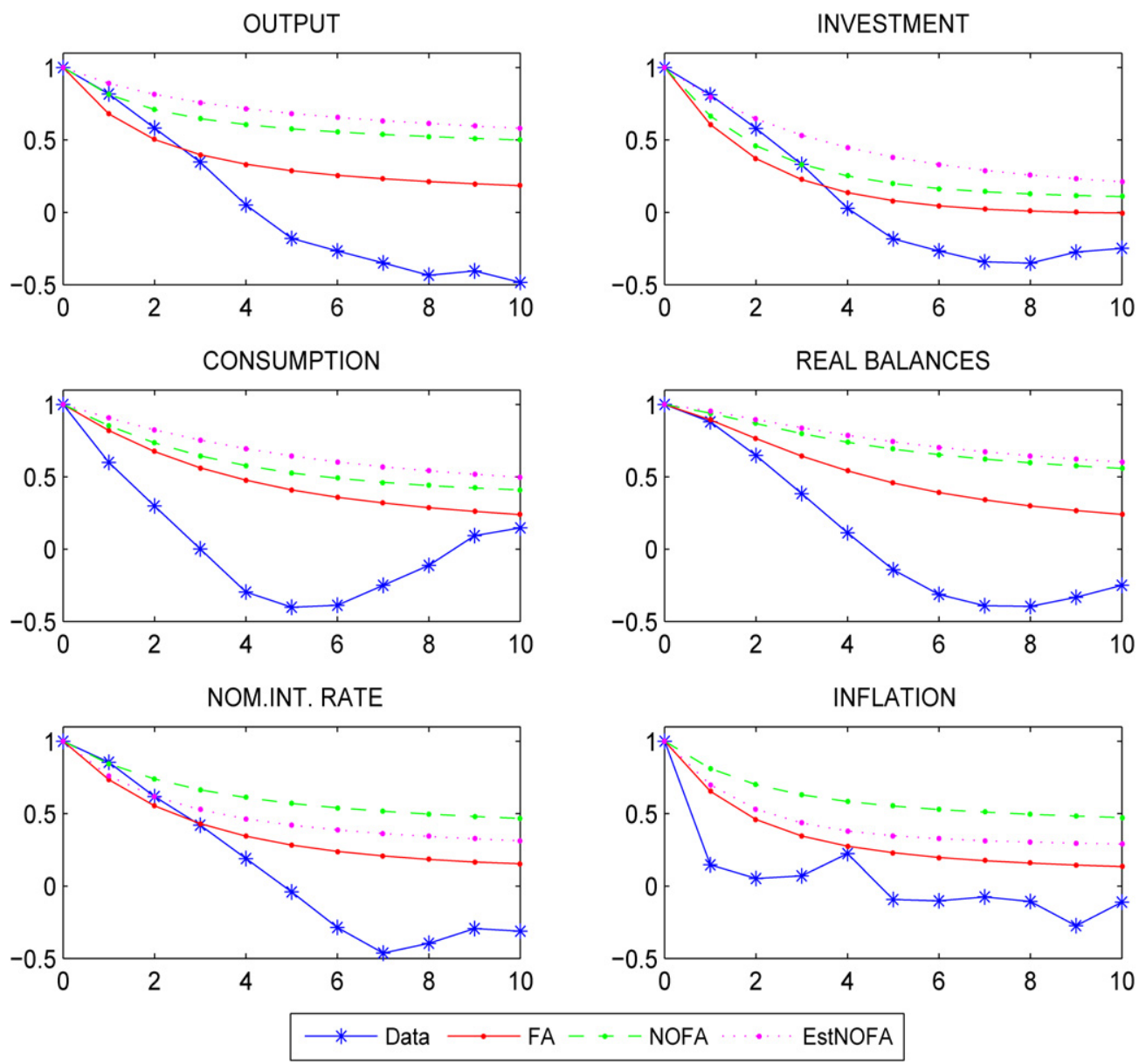

Fig. 6. Autocorrelations. 


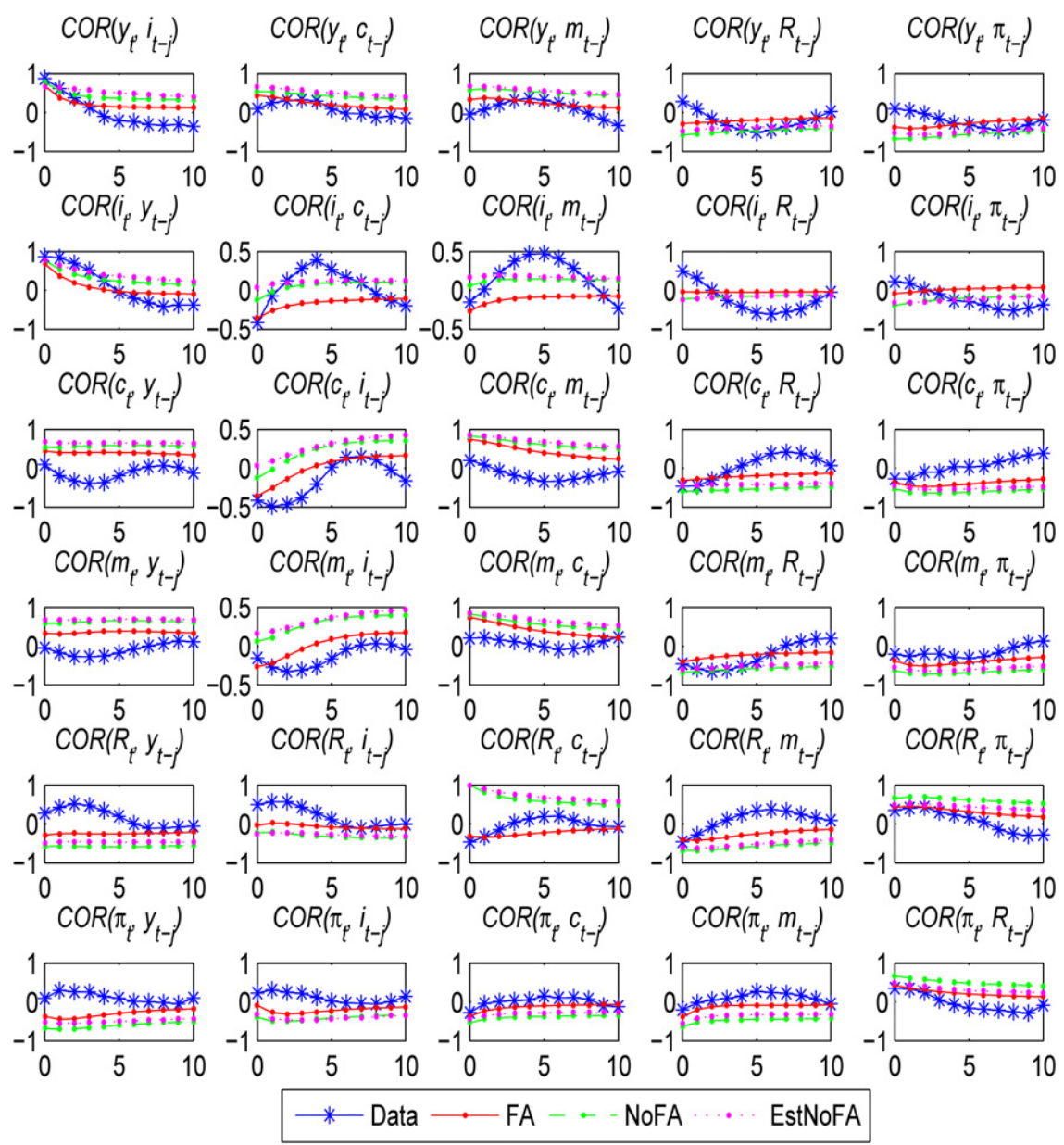

Fig. 7. Cross-correlations.

in the data. In particular, the FA model is better able to capture the cross-correlations between output and lags of investment. Differences between the FA and EstNoFA models are biggest for the cross-correlations involving either consumption or investment. For example, only the FA model predicts the correct sign for the correlations between consumption and lagged investment; nominal interest rates and lagged consumption; and real balances and lagged investment.

\subsection{Variance decompositions}

We next consider the forecast-error variance decompositions for output, investment, consumption, real balances, nominal interest rates, and inflation from in all three models. Tables 4 and 5 show the forecast-error variance decompositions of the variables attributed to each of the five shocks for one- and ten-quarter-ahead horizons, respectively. On the whole, these variance decompositions are very similar for the FA and EstNoFA models.

In all of the models, investment-efficiency shocks account for the bulk of output fluctuations. Ireland (2003) also reports that most of the output variance in his sticky-price model is attributed to investment shocks. Similarly, Justiniano and Primiceri (2006) find that investment shocks account for most of real variable volatility in their model.

In addition, in all three models the investment efficiency shock explains virtually all of the forecast-error variance in investment at both the 1-quarter and 10-quarter horizons, in all cases explaining more than 90 percent of the variance in investment. This suggests that these models require large shocks to account for the co-movement of the investment data with data on output, inflation, nominal interest rate, and real balances. The financial accelerator mechanism provides little improvement in this regard. 
Table 4

One-quarter-ahead forecast-error variance decompositions

\begin{tabular}{|c|c|c|c|c|c|c|}
\hline \multirow[t]{2}{*}{ Variable } & \multirow[t]{2}{*}{ Variance } & \multicolumn{5}{|c|}{ Percentage owing to: } \\
\hline & & Technology & Mon. demand & Policy & Preference & Investment \\
\hline \multicolumn{7}{|c|}{ A. FA model } \\
\hline$y_{t}$ & 0.0064 & 5.44 & 6.34 & 10.83 & 9.76 & 67.6 \\
\hline$i_{t}$ & 0.1490 & 0.01 & 1.08 & 2.47 & 1.59 & 94.8 \\
\hline$c_{t}$ & 0.0036 & 14.52 & 5.78 & 7.58 & 58.32 & 13.8 \\
\hline$m_{t}$ & 0.0060 & 34.93 & 18.71 & 29.53 & 0.00 & 17.25 \\
\hline$R_{t}$ & 0.0004 & 7.93 & 47.12 & 10.15 & 33.29 & 1.51 \\
\hline$\pi_{t}$ & 0.0005 & 84.60 & 0.19 & 13.29 & 1.05 & 0.86 \\
\hline \multicolumn{7}{|c|}{ B. $\operatorname{NoFA} \operatorname{model}(\psi=0)$} \\
\hline$y_{t}$ & 0.0078 & 5.72 & 4.17 & 6.62 & 8.88 & 74.59 \\
\hline$i_{t}$ & 0.2131 & 0.25 & 0.28 & 0.53 & 0.70 & 98.24 \\
\hline$c_{t}$ & 0.0041 & 10.34 & 6.44 & 9.45 & 48.89 & 24.87 \\
\hline$m_{t}$ & 0.0061 & 33.22 & 17.85 & 30.0 & 0.01 & 18.92 \\
\hline$R_{t}$ & 0.0004 & 9.86 & 47.30 & 8.81 & 33.96 & 0.07 \\
\hline$\pi_{t}$ & 0.0005 & 84.29 & 0.33 & 14.53 & 0.84 & 0.00 \\
\hline \multicolumn{7}{|c|}{ C. EstNoFA model } \\
\hline$y_{t}$ & 0.0079 & 8.80 & 4.77 & 9.46 & 10.0 & 66.96 \\
\hline$i_{t}$ & 0.1457 & 0.69 & 0.551 & 1.38 & 1.35 & 96.03 \\
\hline$c_{t}$ & 0.0046 & 13.15 & 5.92 & 10.11 & 57.48 & 13.37 \\
\hline$m_{t}$ & 0.0058 & 37.66 & 12.43 & 37.35 & 0.01 & 12.54 \\
\hline$R_{t}$ & 0.0004 & 3.95 & 68.52 & 5.02 & 22.48 & 0.03 \\
\hline$\pi_{t}$ & 0.0005 & 77.03 & 0.01 & 16.98 & 1.67 & 4.31 \\
\hline
\end{tabular}

Table 5

Ten-quarter-ahead forecast-error variance decompositions

\begin{tabular}{|c|c|c|c|c|c|c|}
\hline \multirow[t]{2}{*}{ Variable } & \multirow[t]{2}{*}{ Variance } & \multicolumn{5}{|c|}{ Percentage owing to: } \\
\hline & & Technology & Mon. demand & Policy & Preference & Investment \\
\hline \multicolumn{7}{|c|}{ A. FA model } \\
\hline$y_{t}$ & 0.0117 & 23.48 & 3.88 & 9.60 & 8.05 & 54.96 \\
\hline$i_{t}$ & 0.2235 & 0.38 & 1.20 & 4.45 & 2.22 & 91.73 \\
\hline$c_{t}$ & 0.0096 & 37.80 & 2.75 & 3.39 & 35.44 & 20.60 \\
\hline$m_{t}$ & 0.0272 & 52.68 & 22.21 & 8.64 & 0.09 & 16.36 \\
\hline$R_{t}$ & 0.0009 & 26.39 & 34.81 & 7.41 & 26.87 & 4.50 \\
\hline$\pi_{t}$ & 0.0009 & 66.10 & 6.95 & 9.10 & 1.41 & 16.42 \\
\hline \multicolumn{7}{|c|}{ B. NoFA model } \\
\hline$y_{t}$ & 0.0168 & 21.01 & 2.22 & 4.07 & 6.42 & 66.26 \\
\hline$i_{t}$ & 0.3735 & 1.52 & 0.18 & 0.39 & 0.66 & 97.23 \\
\hline$c_{t}$ & 0.0096 & 31.67 & 3.15 & 5.41 & 33.21 & 26.55 \\
\hline$m_{t}$ & 0.0286 & 50.35 & 20.97 & 8.55 & 0.07 & 20.07 \\
\hline$R_{t}$ & 0.0009 & 30.65 & 31.25 & 5.18 & 24.78 & 8.14 \\
\hline$\pi_{t}$ & 0.0012 & 54.21 & 3.63 & 7.90 & 0.98 & 33.57 \\
\hline \multicolumn{7}{|c|}{ C. EstNoFA model } \\
\hline$y_{t}$ & 0.0247 & 27.35 & 1.79 & 4.44 & 6.86 & 59.55 \\
\hline$i_{t}$ & 0.3754 & 3.59 & 0.26 & 0.78 & 1.28 & 94.08 \\
\hline$c_{t}$ & 0.0141 & 36.17 & 2.23 & 4.95 & 42.04 & 14.61 \\
\hline$m_{t}$ & 0.0303 & 67.08 & 9.02 & 10.47 & 0.16 & 13.25 \\
\hline$R_{t}$ & 0.0007 & 21.41 & 45.20 & 3.78 & 27.83 & 1.77 \\
\hline$\pi_{t}$ & 0.0009 & 59.94 & 3.72 & 13.48 & 2.39 & 20.46 \\
\hline
\end{tabular}

The variance decompositions also show that in all models the preference shocks are the main driver of consumption at the 1-quarter horizon, but the technology shocks also play a role at the longer horizon. Aggregate technology shocks play a dominant role in inflation fluctuations at short and long-horizons. 
Table 6

One-quarter-ahead forecast-error variance decompositions: excluding investment shocks

\begin{tabular}{|c|c|c|c|c|c|c|}
\hline \multirow[t]{2}{*}{ Variable } & \multirow[t]{2}{*}{ Variance } & \multicolumn{5}{|c|}{ Percentage owing to: } \\
\hline & & Technology & Mon. demand & Policy & Preference & Investment \\
\hline \multicolumn{7}{|c|}{ A. FA model } \\
\hline$y_{t}$ & 0.0021 & 16.82 & 19.57 & 33.47 & 30.14 & 0 \\
\hline$i_{t}$ & 0.0077 & 0.18 & 20.94 & 48.01 & 30.86 & 0 \\
\hline$c_{t}$ & 0.0031 & 16.84 & 6.71 & 8.80 & 67.65 & 0 \\
\hline$m_{t}$ & 0.0050 & 41.70 & 22.61 & 35.69 & 0.00 & 0 \\
\hline$R_{t}$ & 0.0004 & 8.06 & 47.84 & 10.30 & 33.80 & 0 \\
\hline$\pi_{t}$ & 0.0005 & 85.33 & 0.19 & 13.41 & 1.06 & 0 \\
\hline \multicolumn{7}{|c|}{ B. NoFA model $(\psi=0)$} \\
\hline$y_{t}$ & 0.0020 & 22.54 & 16.44 & 26.06 & 34.96 & 0 \\
\hline$i_{t}$ & 0.0037 & 14.25 & 15.91 & 29.97 & 39.87 & 0 \\
\hline$c_{t}$ & 0.0031 & 13.79 & 8.58 & 12.57 & 65.08 & 0 \\
\hline$m_{t}$ & 0.0050 & 40.97 & 22.02 & 37.0 & 0.01 & 0 \\
\hline$R_{t}$ & 0.0004 & 9.86 & 47.33 & 8.82 & 33.99 & 0 \\
\hline$\pi_{t}$ & 0.0005 & 84.30 & 0.33 & 14.53 & 0.84 & 0 \\
\hline \multicolumn{7}{|c|}{ C. EstNoFA model } \\
\hline$y_{t}$ & 0.0026 & 26.63 & 14.43 & 28.64 & 30.29 & 0 \\
\hline$i_{t}$ & 0.0058 & 17.38 & 13.73 & 34.90 & 33.98 & 0 \\
\hline$c_{t}$ & 0.0040 & 15.12 & 6.84 & 11.67 & 66.36 & 0 \\
\hline$m_{t}$ & 0.0051 & 43.06 & 14.22 & 42.71 & 0.02 & 0 \\
\hline$R_{t}$ & 0.0004 & 3.95 & 68.54 & 5.02 & 22.49 & 0 \\
\hline$\pi_{t}$ & 0.0005 & 80.49 & 0.01 & 17.75 & 1.75 & 0 \\
\hline
\end{tabular}

Monetary policy shocks account for a small fraction of the variance in output and investment in the no-financialaccelerator models, echoing the findings of Christiano et al. (2005). However, monetary policy shocks account for a slightly larger share of the one-quarter-ahead output and inflation variance when the accelerator is active. Policy shocks also have effects on output fluctuations at longer horizons in the presence of the financial accelerator. For example, monetary policy shocks account for over 9.6 percent of ten-quarter-ahead forecast variance error of output in the FA model, but 4.4 percent in the absence of the accelerator. Table 6 reports the one-quarter-ahead forecast error variance when we simulate the models setting the variance of the investment shocks to zero. Here we see more clearly that the financial accelerator is increasing the importance of monetary policy shocks for fluctuations in output and investment.

\section{Conclusion}

In this paper, we have estimated and simulated a sticky-price model with financial frictions along the lines of Bernanke et al. (1999) financial accelerator mechanism. Unlike Bernanke et al. (1999), the debt contract in our model is nominal, allowing for debt deflation effects, and the monetary authorities can respond to output and money growth in addition to inflation deviations. Our objectives are to determine whether the financial accelerator can improve the sticky-price model's ability to fit post-1979 US data, and to assess the nature of the mechanism's role in the estimated model's dynamics.

Using a maximum-likelihood procedure with a Kalman filter, we estimate structural parameters for two versions of the model: one with and one without the financial accelerator. The estimated value of a key parameter in the accelerator mechanism, the elasticity of the external finance premium with respect to firm leverage, is statistically significant and close to values usually used in typical calibrations of DSGE models with a financial accelerator. A likelihood-ratio test easily rejects the estimated model with no financial friction in favor of the model with the financial accelerator. Thus, there is an improvement in the model's fit with the data when the financial accelerator is active. We argue that this is, in part, because the accelerator better captures the joint dynamics of output and investment seen in the data.

The presence of a financial accelerator mechanism in our model significantly amplifies and propagates the impact of demand-side shocks - monetary policy, money demand, and preference shocks—on investment and the price 
of capital. However, the financial accelerator mechanism dampens (pushes down) the rise of investment following positive supply-side shocks-technology and investment-efficiency shocks. The role of the financial accelerator in investment fluctuations, therefore, depends on the nature of the shock.

We also find that the initial impact of the accelerator on output and inflation is relatively minor in our model. This is partly due to the aggressive response of the monetary authority to output variations produced by our estimated policy rule. Nonetheless, the presence of the accelerator extends the horizon over which monetary policy shocks play a role in output fluctuations.

While these results are interesting, the empirical model still requires large and persistent investment-efficiency shocks to fit the data. This suggests that one avenue for future model development should explore alternative formulations for the elements of the model related to investment. Another useful extension to the model would be to explore other utility functions that make households less willing or able to substitute consumption intertemporally, since this could affect the impact of the accelerator on aggregate output. This might be achieved by households themselves facing a financial friction. Finally, future work should consider whether aggregate financial data can be used in the estimation to make a stronger link between our findings and firm financing.

\section{Acknowledgments}

We thank two anonymous referees, Carlos De Resende, Simon Gilchrist, Peter Ireland, Kevin Moran, Fabio Natalucci, Brenda Spotton Visano, and Pierre St-Amant for their very helpful comments and discussion. We are solely responsible for any remaining errors.

\section{Appendix A. The non-linear equilibrium system}

$$
\begin{aligned}
& \frac{e_{t} c_{t}^{-\frac{1}{\gamma}}}{c_{t}^{\frac{\gamma-1}{\gamma}}+b_{t}^{1 / \gamma} m_{t}^{\frac{\gamma-1}{\gamma}}=\lambda_{t} ;} \\
& \left(\frac{b_{t} c_{t}}{m_{t}}\right)^{1 / \gamma}=\frac{R_{t}-1}{R_{t}} ; \\
& \frac{\eta}{1-h_{t}}=\lambda_{t} w_{t} ; \\
& \frac{\lambda_{t}}{R_{t}}=\beta E_{t}\left(\frac{\lambda_{t+1}}{\pi_{t+1}}\right) ; \\
& z_{t}=\alpha \xi_{t} \frac{y_{t}}{k_{t}} ; \\
& w_{t}=(1-\alpha) \xi_{t} \frac{y_{t}}{h_{t}} ; \\
& y_{t}=k_{t}^{\alpha}\left(A_{t} h_{t}\right)^{1-\alpha} ; \\
& y_{t}=c_{t}+i_{t} ; \\
& \frac{\tilde{p}_{t}}{p_{t}}=\frac{\theta}{\theta-1} \frac{E_{t} \sum_{l=0}^{\infty}(\beta \phi)^{l} \lambda_{t+l} y_{t+l} \xi_{t+l}}{E_{t} \sum_{l=0}^{\infty}(\beta \phi)^{l} \lambda_{t+l} y_{t+l} \pi^{l} \Pi_{i=1}^{l} \pi_{t+i}^{-1}} ; \\
& 1=\phi\left(\frac{\pi}{\pi_{t}}\right) \\
& E_{t} f_{t+1}=E_{t}\left[S\left(\frac{n_{t+1}}{q_{t} k_{t+1}}\right) R_{t} / \pi_{t+1}\right] ; \\
& E_{t} f_{t+1}=E_{t}\left[\frac{z_{t+1}+(1-\delta) q_{t+1}}{p_{t}}\right] ; \\
& E_{t} n_{t+1}=v\left[f_{t} q_{t-1} k_{t}-E_{t-1} f_{t}\left(q_{t-1} k_{t}-n_{t}\right)\right]+(1-v) g_{t} ;
\end{aligned}
$$




$$
\begin{aligned}
& k_{t+1}=x_{t} i_{t}+(1-\delta) k_{t} ; \\
& q_{t} x_{t}=1+\chi\left(\frac{i_{t}}{k_{t}}-\delta\right) ; \\
& \frac{R_{t}}{R}=\left(\frac{\pi_{t}}{\pi}\right)^{\varrho_{\pi}}\left(\frac{y_{t}}{y}\right)^{\varrho_{y}}\left(\frac{\mu_{t}}{\mu}\right)^{\varrho_{\mu}} \exp \left(\varepsilon_{R t}\right) ; \\
& \mu_{t}=\frac{m_{t} \pi_{t}}{m_{t-1}} .
\end{aligned}
$$

\section{Appendix B. The steady-state equilibrium}

$$
\begin{aligned}
& q=1 ; \\
& \xi=\frac{\theta-1}{\theta} ; \\
& R=\pi / \beta \\
& f=S R / \pi \\
& f=z+1-\delta ; \\
& \lambda c=\left[1+b\left(\frac{\pi}{\pi-\beta}\right)^{\gamma-1}\right]^{-1} ; \\
& \lambda m=\lambda c b\left(\frac{\pi}{\pi-\beta}\right)^{\gamma} ; \\
& \frac{k}{y}=\alpha \frac{\xi}{z} ; \\
& \frac{c}{y}=1-\delta \frac{k}{y} ; \\
& w h \lambda=\frac{(1-\alpha)(\lambda c) \xi}{c / y} ; \\
& h=\frac{w h \lambda}{\eta+w h \lambda} ; \\
& y=A h\left(\frac{k}{y}\right)^{\alpha /(1-\alpha)} ; \\
& i=\delta k
\end{aligned}
$$

\section{Appendix C. The log-linearized equilibrium system}

$$
\begin{aligned}
& ((1-\gamma) \lambda c-1) \hat{c}_{t}=\gamma \hat{\lambda}_{t}+\frac{\lambda m(R-1)}{R}\left(\hat{b}_{t}+(\gamma-1) \hat{m}_{t}\right)-\gamma \hat{e}_{t} \\
& \frac{\gamma \hat{R}_{t}}{(R-1)}=\hat{b}_{t}+\hat{c}_{t}-\hat{m}_{t} \\
& h \hat{h}_{t}=(1-h)\left(\hat{w}_{t}+\hat{\lambda}_{t}\right) \\
& \hat{y}_{t}=\alpha \hat{k}_{t}+(1-\alpha) \hat{h}_{t}+(1-\alpha) \hat{A}_{t} \\
& y \hat{y}_{t}=c \hat{c}_{t}+i \hat{i}_{t} \\
& \hat{w}_{t}=\hat{y}_{t}+\hat{\xi}_{t}-\hat{h}_{t} \\
& \hat{z}_{t}=\hat{y}_{t}+\hat{\xi}_{t}-\hat{k}_{t} \\
& \hat{\mu}_{t}=\hat{m}_{t}-\hat{m}_{t-1}+\hat{\pi}_{t}
\end{aligned}
$$




$$
\begin{aligned}
& \hat{R}_{t}=\varrho_{\pi} \hat{\pi}_{t}+\varrho_{\mu} \hat{\mu}_{t}+\varrho_{y} \hat{y}_{t}+\varepsilon_{R t} \\
& \hat{f}_{t}=\frac{z}{f} \hat{z}_{t}+\frac{1-\delta}{f} \hat{q}_{t}-\hat{q}_{t-1} ; \\
& \hat{q}_{t}=\chi\left(\hat{i}_{t}-\hat{k}_{t}\right)-\hat{x}_{t} \\
& \hat{\pi}_{t}=\beta \hat{\pi}_{t+1}+\frac{(1-\beta \phi)(1-\phi)}{\phi} \hat{\xi}_{t} ; \\
& \hat{\lambda}_{t+1}=\hat{\lambda}_{t}-\hat{R}_{t}+\hat{\pi}_{t+1} ; \\
& \hat{k}_{t+1}=\delta \hat{i}_{t}+\delta \hat{x}_{t}+(1-\delta) \hat{k}_{t} ; \\
& \hat{f}_{t+1}=\hat{R}_{t}-\hat{\pi}_{t+1}+\psi\left(\hat{q}_{t}+\hat{k}_{t+1}-\hat{n}_{t+1}\right) ; \\
& \frac{\hat{n}_{t+1}}{v f}=\frac{k}{n} \hat{f}_{t}-\left(\frac{k}{n}-1\right)\left(\hat{R}_{t-1}-\hat{\pi}_{t}\right)-\psi\left(\frac{k}{n}-1\right)\left(\hat{k}_{t}+\hat{q}_{t-1}\right)+\left(\psi\left(\frac{k}{n}-1\right)+1\right) \hat{n}_{t} .
\end{aligned}
$$

\section{References}

Bernanke, B., Gertler, M., 1989. Agency costs, net worth and business fluctuations. American Economic Review 79, 14-31.

Bernanke, B., Gertler, M., 2000, Monetary policy and asset price volatility. Working paper No. 7559. NBER.

Bernanke, B., Gertler, M., Gilchrist, S., 1999. The financial accelerator in a quantitative business cycle framework. In: Handbook of Macroeconomics. North-Holland, Amsterdam.

Blanchard, O.J., Kahn, C.M., 1980. The solution of linear difference models under rational expectations. Econometrica 48, 1305-1311.

Bouakez, H., Cardia, E., Ruge-Murcia, F., 2005. Habit formation and the persistence of monetary policy shocks. Journal of Monetary Economics 52 $1073-1088$.

Calvo, G.A., 1983. Staggered prices in a utility-maximizing framework. Journal of Monetary Economics 12, $383-398$.

Carlstrom, G., Fuerst, T.S., 1997. Agency costs, net worth, business fluctuations: A computable general equilibrium analysis. American Economic Review 87, 893-910.

Cespedes, L.F., Chang, R., Velasco, A., 2004. Balance sheets and exchange rate policy. American Economic Review 94, 1183-1193.

Christiano, L.J., Motto, R., Rostagno, M., 2003. The Great Depression and the Friedman-Schwartz hypothesis. Journal of Money, Credit, Banking 35, 1119-1197.

Christiano, L., Eichenbaum, M., Evans, C., 2005. Nominal rigidities and the dynamic effects of a shock to monetary policy. Journal of Political Economy 113, 1-45.

Cook, D., 1999. The liquidity effect and money demand. Journal of Monetary Economics 43, 377-390.

Dib, A., 2003. An estimated Canadian DSGE model with nominal and real rigidities. Canadian Journal of Economics 36, 949-972.

Dib, A., 2006. Nominal rigidities and monetary policy in Canada. Journal of Macroeconomics 28, 285-304.

Elekdag, S., Justiniano, A., Tchakarov, I., 2006. An estimated small open economy model of the financial accelerator. IMF Staff Papers 53 , 219-241.

Fisher, I., 1933. The debt-deflation theory of great depressions. Econometrica 1, 337-357.

Fisher, J.D., 2002. The dynamic effects of neutral and investment-specific technology shocks. Working paper No. 2002-14. Federal Reserve Bank of Chicago (Journal of Money, Credit, Banking, in press).

Fukunaga, I., 2002. Financial accelerator effects in Japan's business cycles. Working paper No. 2002-2. Bank of Japan.

Gertler, M., Gilchrist, S., Natalucci, F., 2003. External constraints on monetary policy and the financial accelerator. Working paper No. 139. BIS (Journal of Money, Credit, Banking, in press)

Gilchrist, S., 2004. Financial markets and financial leverage in a two-country world economy. In: Banking Market Structure and Monetary Policy. Central Bank of Chile, Santiago.

Greenwood, J., Hercowitz, Z., Huffman, G., 1988. Investment, capacity utilization, the real business cycle. American Economic Review 78, 402417.

Greenwood, J., Hercowitz, Z., Krusell, P., 2000. The role of investment-specific technological change in the business cycle. European Economic Review 44, 91-115.

Hall, S., 2001. Financial accelerator effects in UK business cycles. Working paper No. 150. Bank of England.

Hamilton, J.D., 1994. Time Series Analysis. Princeton Univ. Press, Princeton.

Iacoviello, M., 2005. House prices, borrowing constraints and monetary policy in the business cycle. American Economic Review 95, 739-764.

Ireland, P.N., 2003. Endogenous money or sticky prices? Journal of Monetary Economics 50, 1623-1648.

Primiceri, G.E., 2006. The time varying volatility of macroeconomic fluctuations, Working paper No. 12022. NBER.

Kiyotaki, N., Moore, J., 1997. Credit cycles. The Journal of Political Economy 105, 211-248.

Meier, A., Müller, G.J., 2006. Fleshing out the monetary transmission mechanism: output composition and the role of financial frictions. Journal of Money, Credit, Banking 38, 1999-2133.

Taylor, J.B., 1993. Discretion versus policy rules in practice. Carnegie-Rochester Conference Series on Public Policy 39, 195-214.

Tovar C., 2006. Devaluations, output, the balance sheet effect: A structural econometric analysis. Working Paper No. 215. Bank for International Settlements.

Yun, T., 1996. Nominal price rigidity, money supply endogeneity, business cycles. Journal of Monetary Economics 37, $345-370$. 